\title{
Water switched reversible thermochromism in organic salt of sulfonated anil
}

\author{
Arshid A. Ganie and Aijaz A. Dar*
}

[a] Dr.Aljaz Ahmad Dar* and Arshid A. Ganie

Department of Chemistry, Inorganic Section, University of Kashmir, Hazratbal, Srinagar, J\&K-190006, India

emil: aijazpapers@gmail.com/daraijaz@uok.edu.in

Phone: +91-9596034885

Figure ESI-1. FT-IR spectrum of $\mathbf{1 a}$.

Figure ESI-2. FT-IR spectrum of $1 \mathrm{C}$.

Figure ESI-3. FT-IR spectrum of 1G.

Figure ESI-4. FT-IR spectrum of $\mathbf{1 H}$.

Figure ESI-5. FT-IR spectrum of 1RT.

Figure ESI-6. FT-IR spectrum of 2.

Figure ESI-7. FT-IR spectrum of $\mathbf{2 H}$.

Figure ESI-8. ${ }^{1} \mathrm{H}-\mathrm{NMR}$ spectrum of 1 a reported in DMSO-d ${ }_{6}$ at $500 \mathrm{MHz}$.

Figure ESI-9. ${ }^{1} \mathrm{H}-\mathrm{NMR}$ spectrum of 1 reported in $\mathrm{DMSO}_{-} \mathrm{d}_{6}$ at $500 \mathrm{MHz}$.

Figure ESI-10. ${ }^{1} \mathrm{H}-\mathrm{NMR}$ spectrum of 2 reported in DMSO-d $\mathrm{d}_{6}$ at $500 \mathrm{MHz}$.

Figure ESI-11. 2D Network formed by sulfonate ions with aid of lattice water molecules in $\mathbf{1 .}$

Figure ESI-12. Cyclic molecular cluster in 2.

Figure ESI-13. Hirshfeld Surface of 1.

Table ESI-1.Hirshfeld surface property information of $\mathbf{1 .}$

Figure ESI-14. Total and individual figerprint plots of 1.

Table ESI-2.Percentage of total surface area for close contacts between atoms inside and outside in 1.

Figure ESI-15. Hirshfeld Surface of 2.

Table ESI-3.Hirshfeld surface property information of 2.

Figure ESI-16. Total and individual figerprint plots of 2.

Table ESI-4.Percentage of total surface area for close contacts between atoms inside and outside in 2.

Figure ESI-17.Merged K-M plots of 1, 2 and their different forms.

Figure ESI-18.MergedTauc of 1, 2 and their different forms.

Figure ESI-19. TGA-DTA Thermograms of 1a.

Figure ESI-20. TGA-DTA Thermograms of 1.

Figure ESI-21. TGA-DTA Thermograms of 1G.

Figure ESI-22. TGA-DTA Thermograms of $\mathbf{1 H}$.

Figure ESI-23. TGA-DTA Thermograms of 1RT.

Figure ESI-24. TGA-DTA Thermograms of 1RT-7'

Figure ESI-25. TGA-DTA Thermograms of 2.

Figure ESI-26. TGA-DTA Thermograms of $\mathbf{2 H}$.

Figure ESI-27.Merged DTA curves of 1 and its different forms.

Figure ESI-28.Merged DTA curves of 1, 2 and their different forms.

Figure ESI-29: Merged TGA Thermograms of 1, 2 and their different forms.

Figure ESI-30.Comparative P-xrd plots 1 and its different forms. 


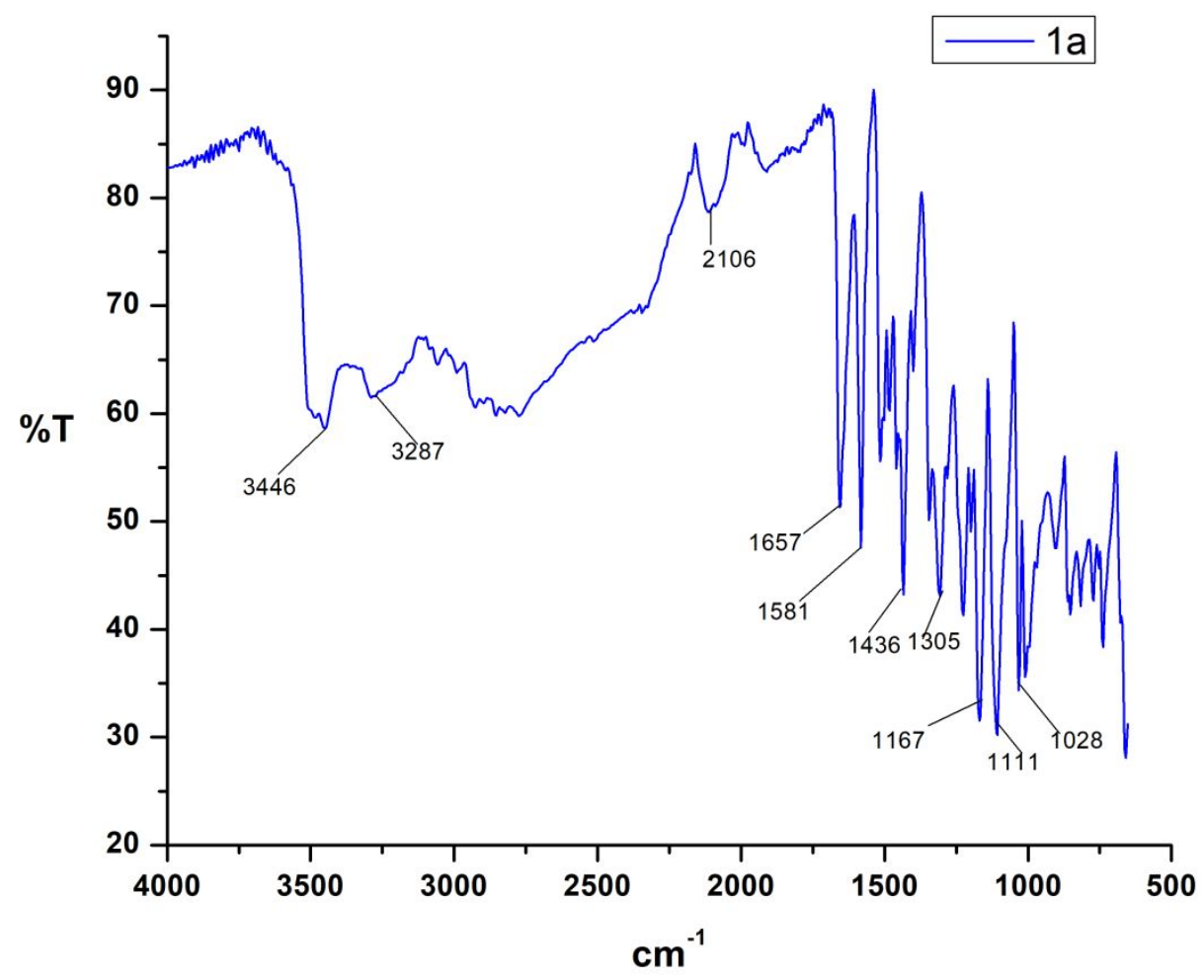

Figure ESI-1: FT-IR spectrum of 1a. 


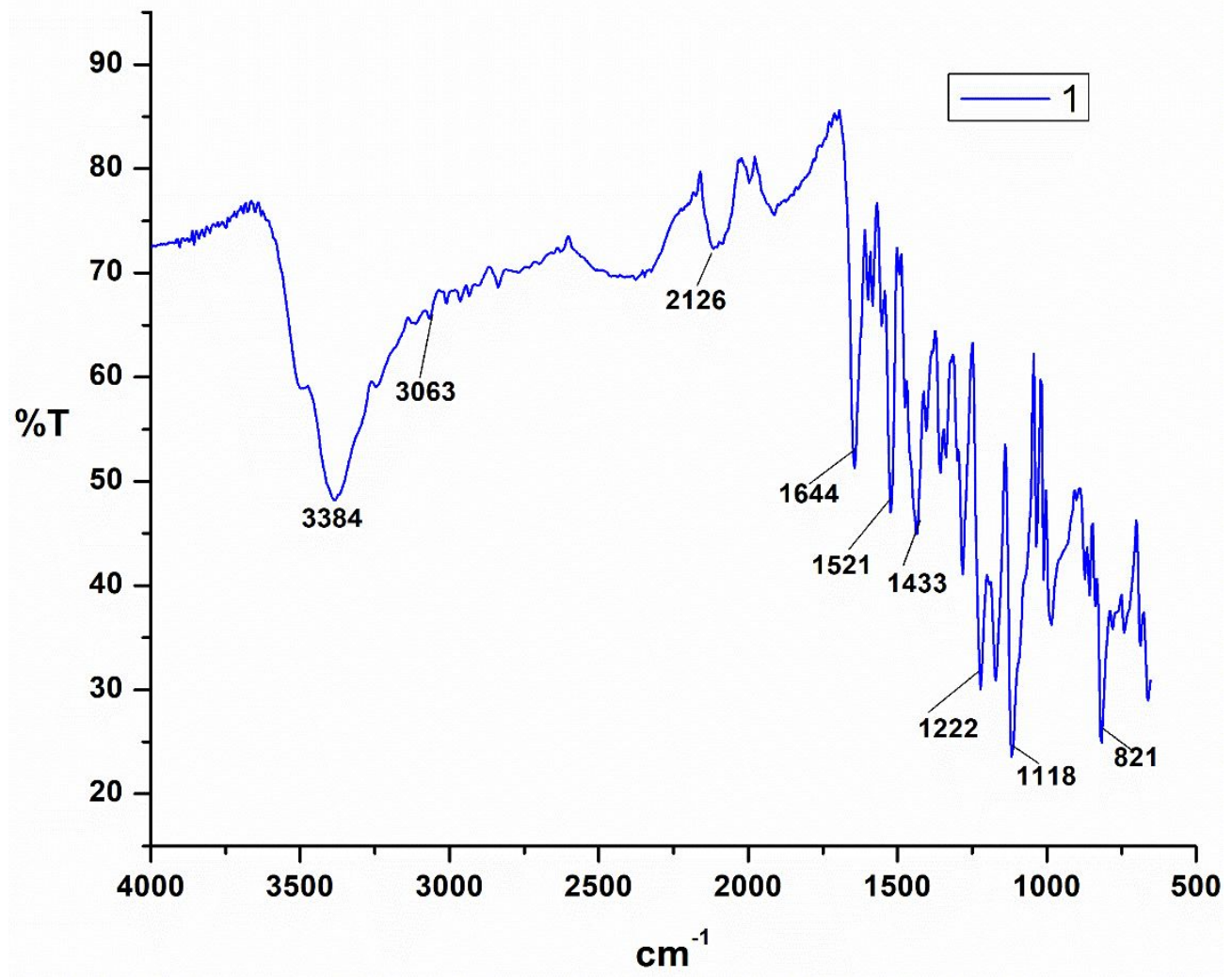

Figure ESI-2: FT-IR spectrum of 1.

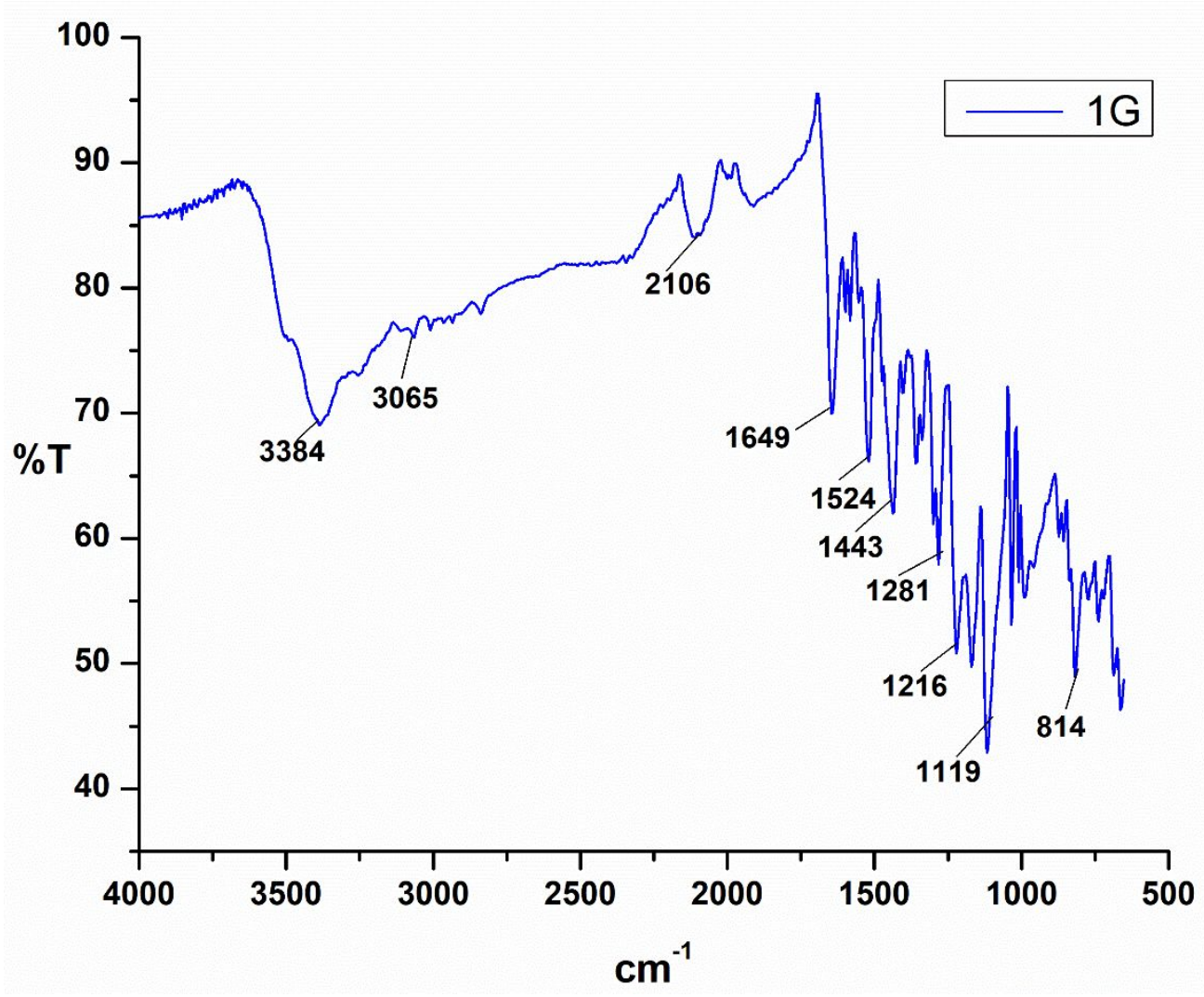


Figure ESI-3: FT-IR spectrum of 1G.

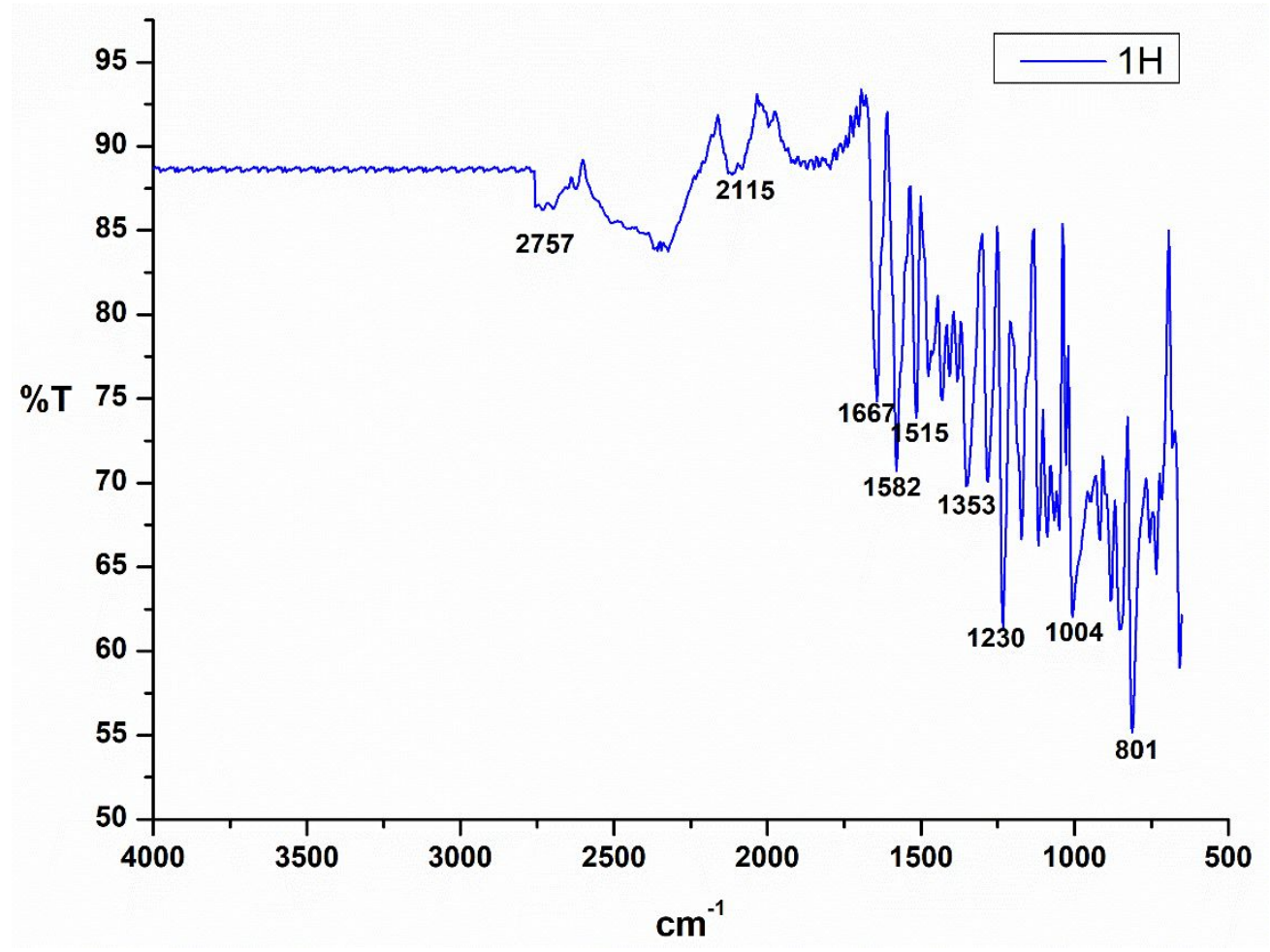

Figure ESI-4: FT-IR spectrum of $\mathbf{1 H}$.

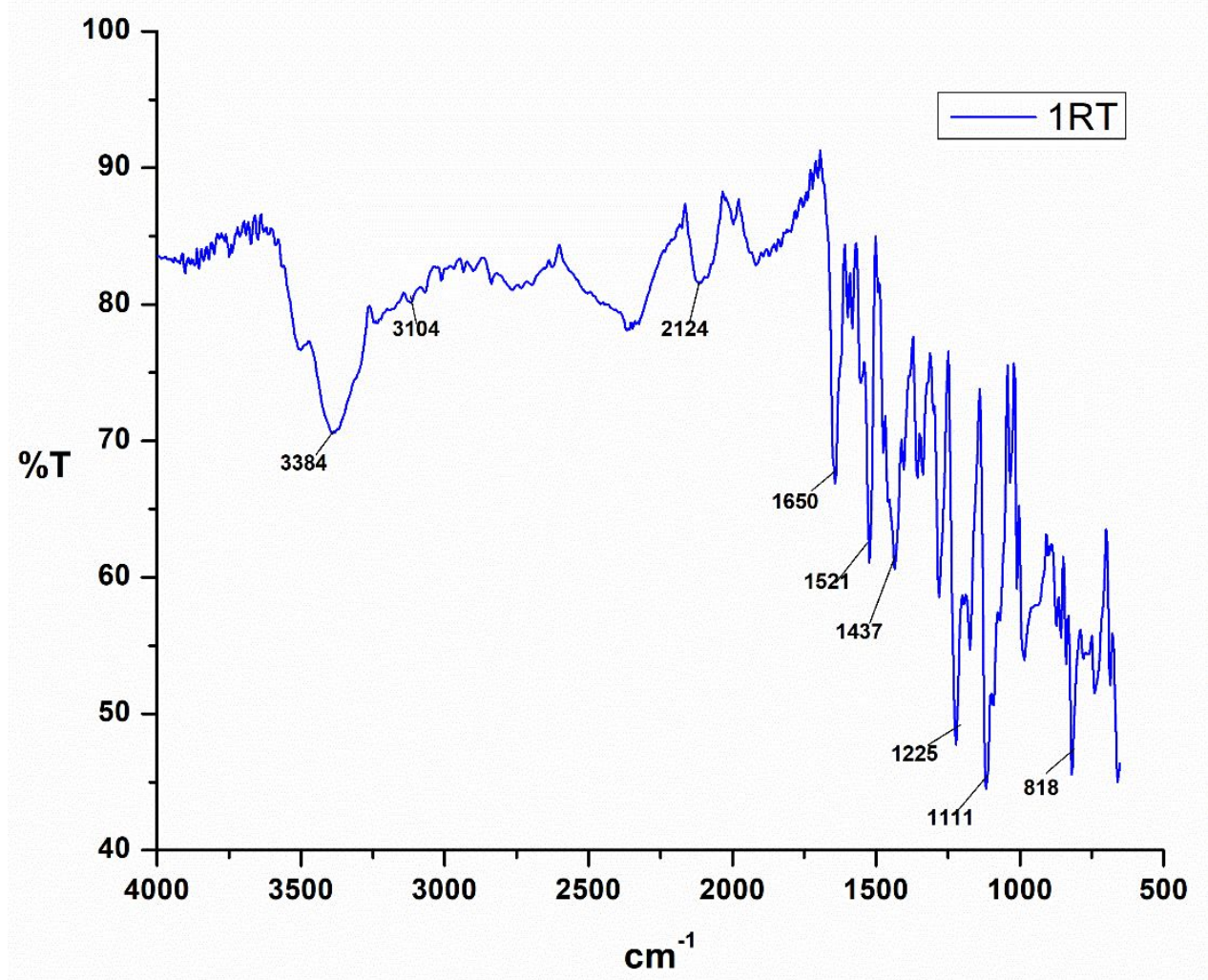


Figure ESI-5: FT-IR spectrum of 1RT.

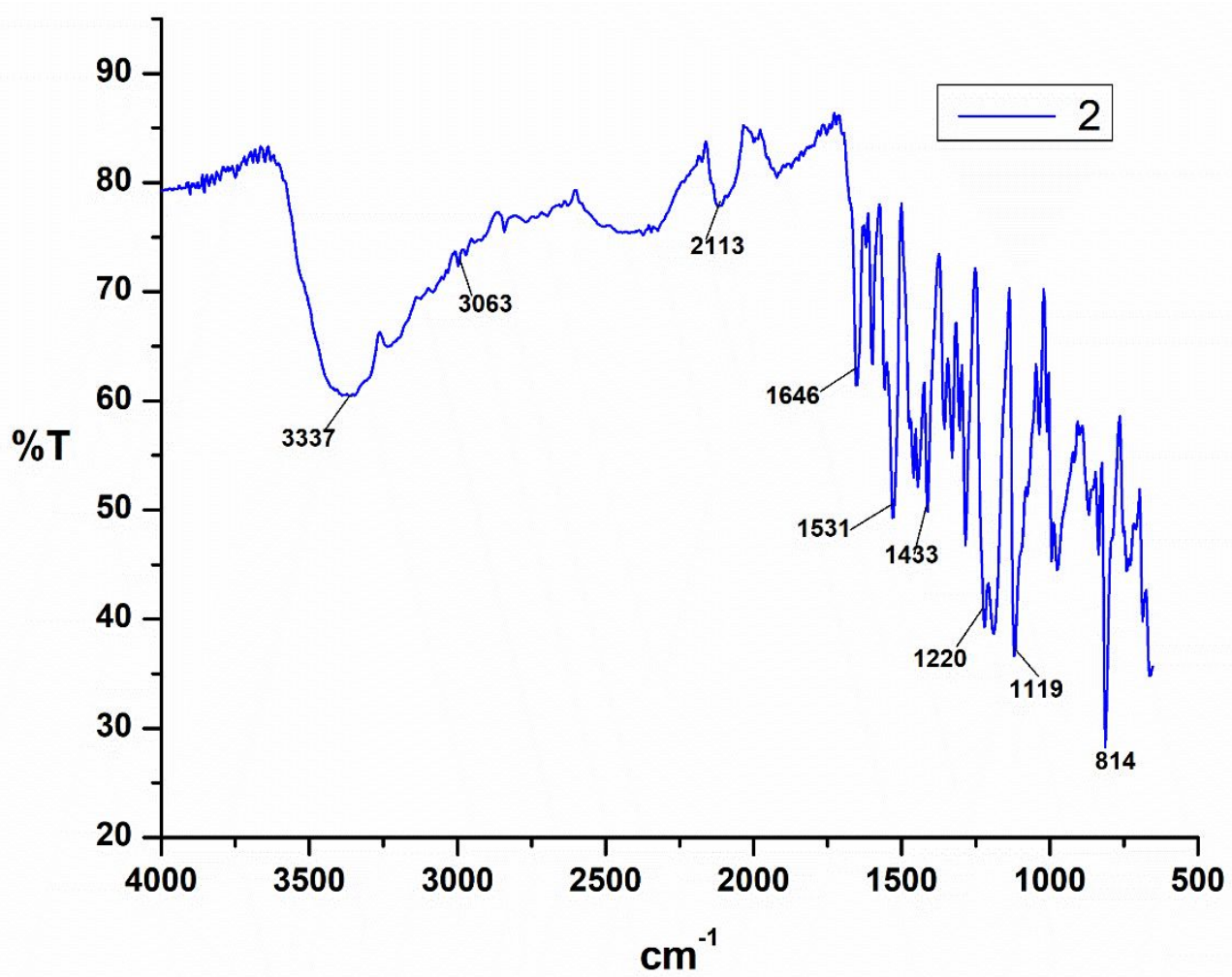

Figure ESI-6: FT-IR spectrum of 2.

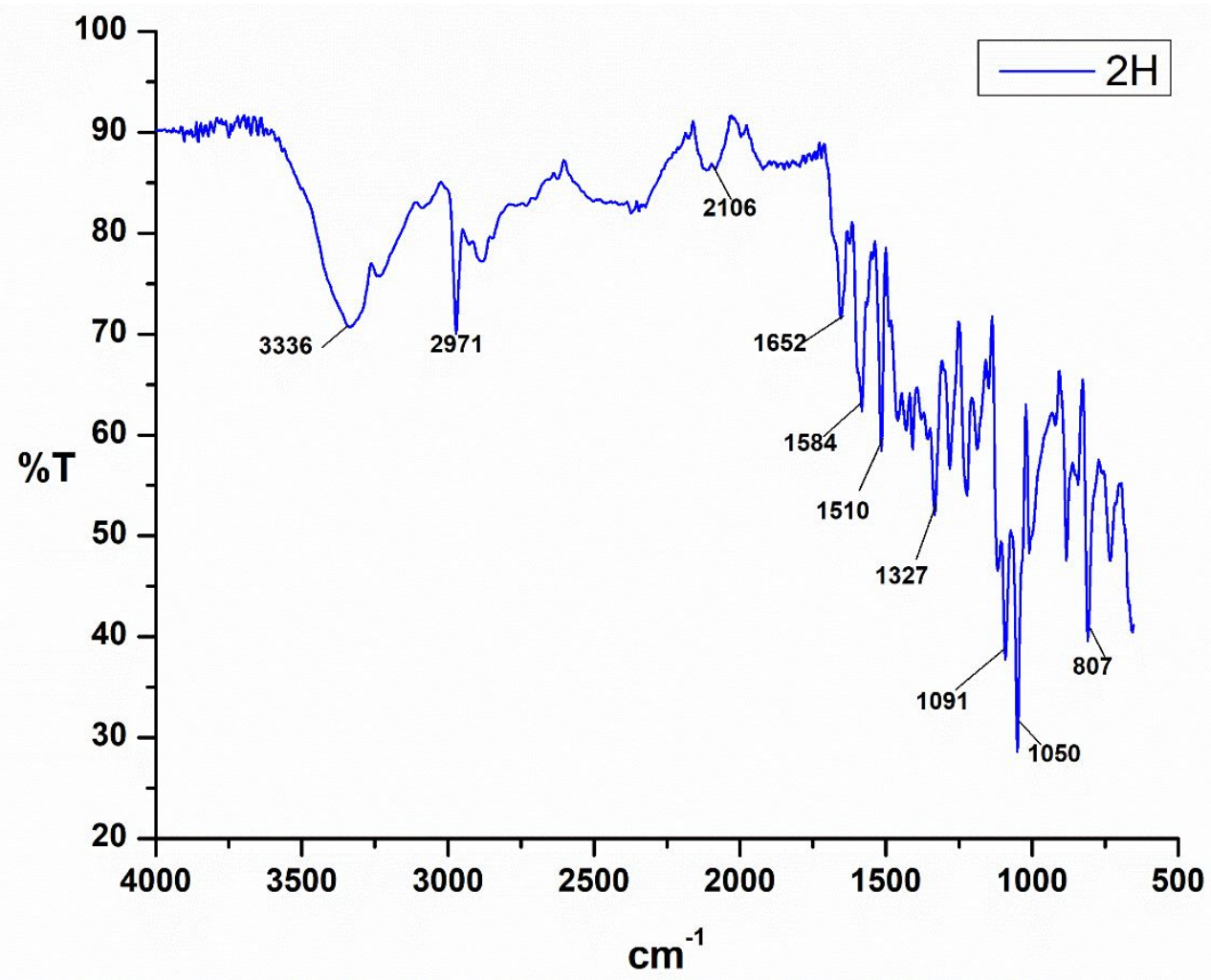


Figure ESI-7: FT-IR spectrum of 2-H.

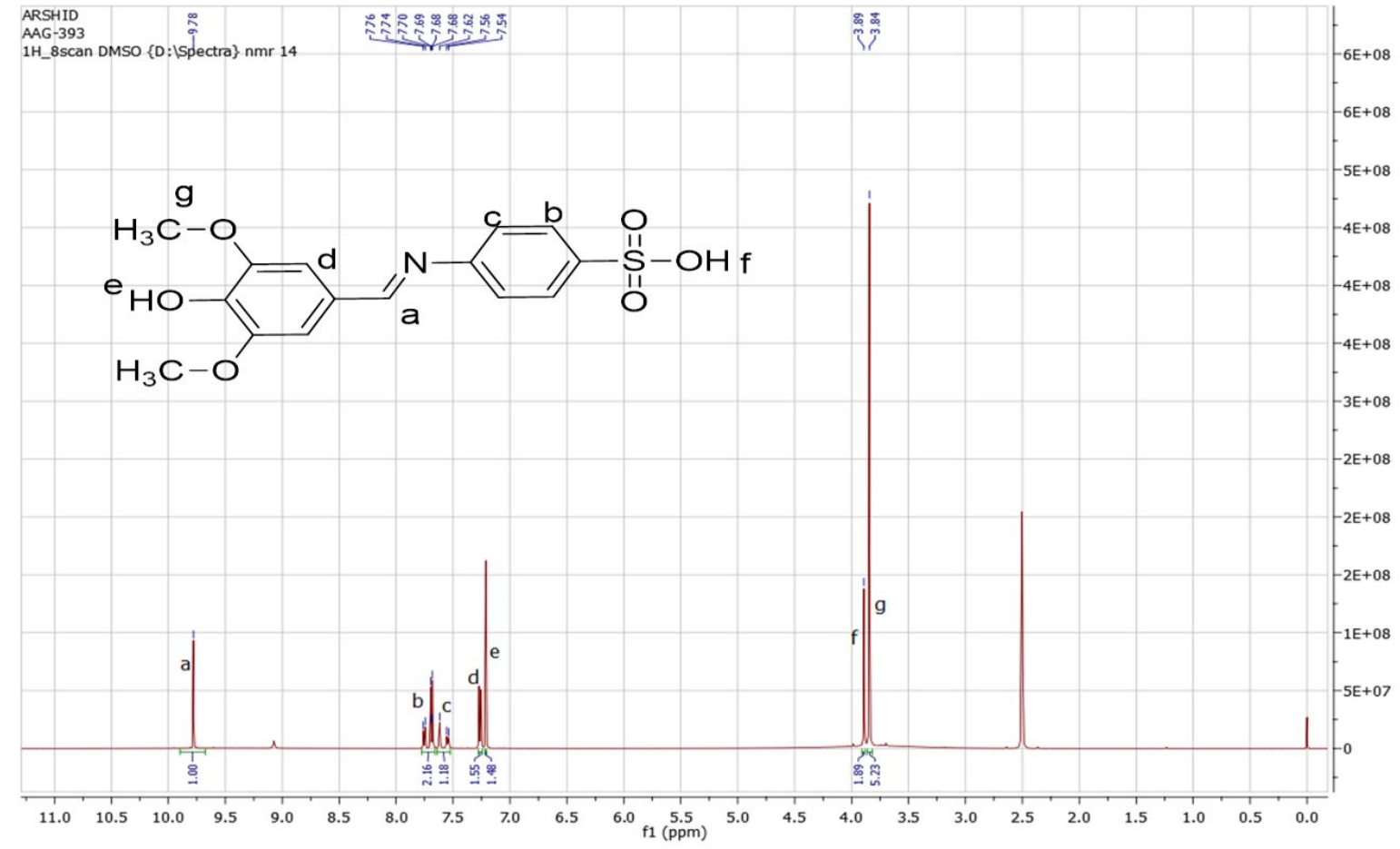

Figure ESI-8. ${ }^{1} \mathrm{H}-\mathrm{NMR}$ spectrum of 1a reported in DMSO-d ${ }_{6}$ at $500 \mathrm{MHz}$.

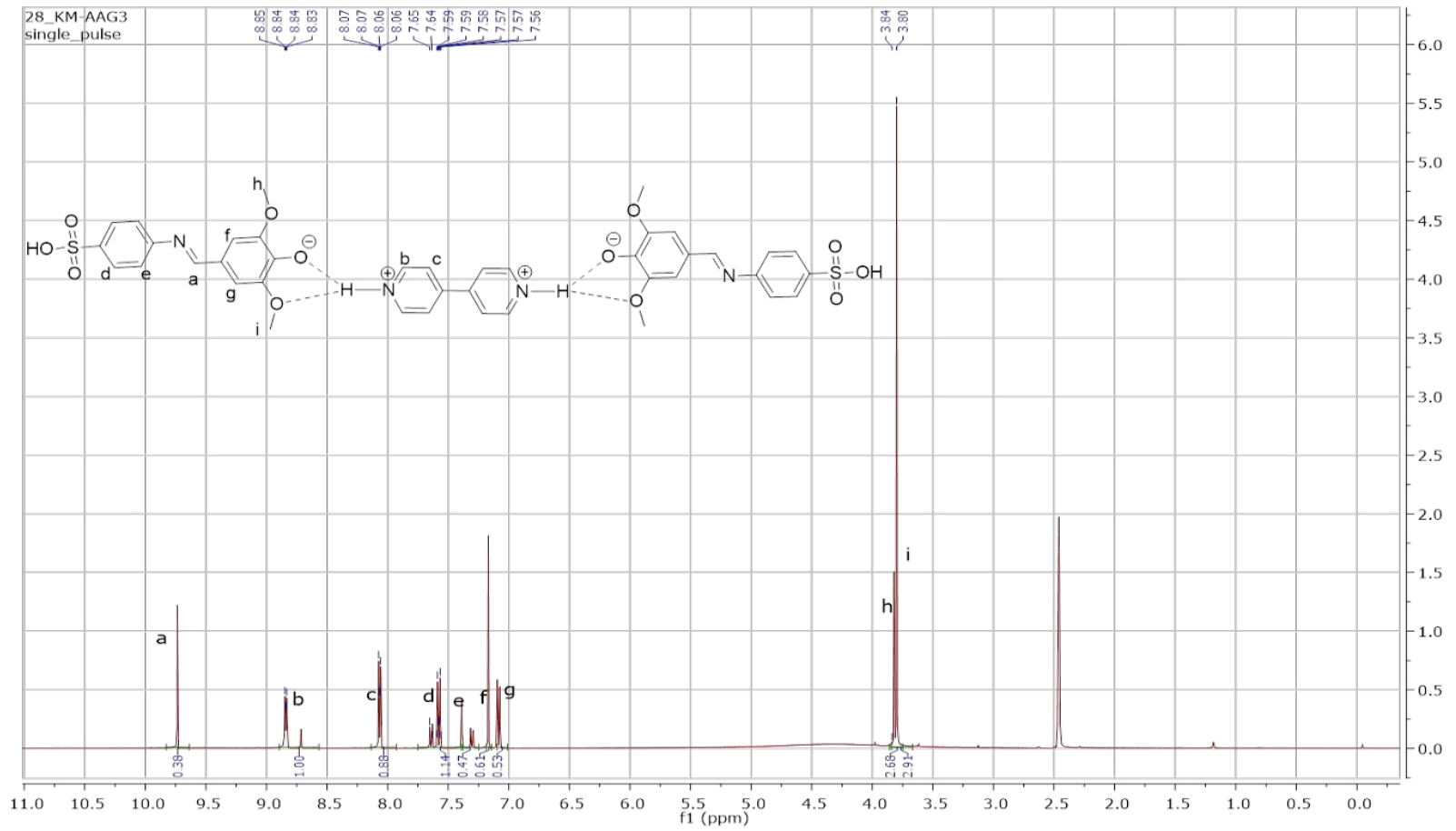

Figure ESI-9: ${ }^{1} \mathrm{H}-\mathrm{NMR}$ spectrum of 1reported in DMSO-d $\mathrm{d}_{6}$ at $500 \mathrm{MHz}$. 


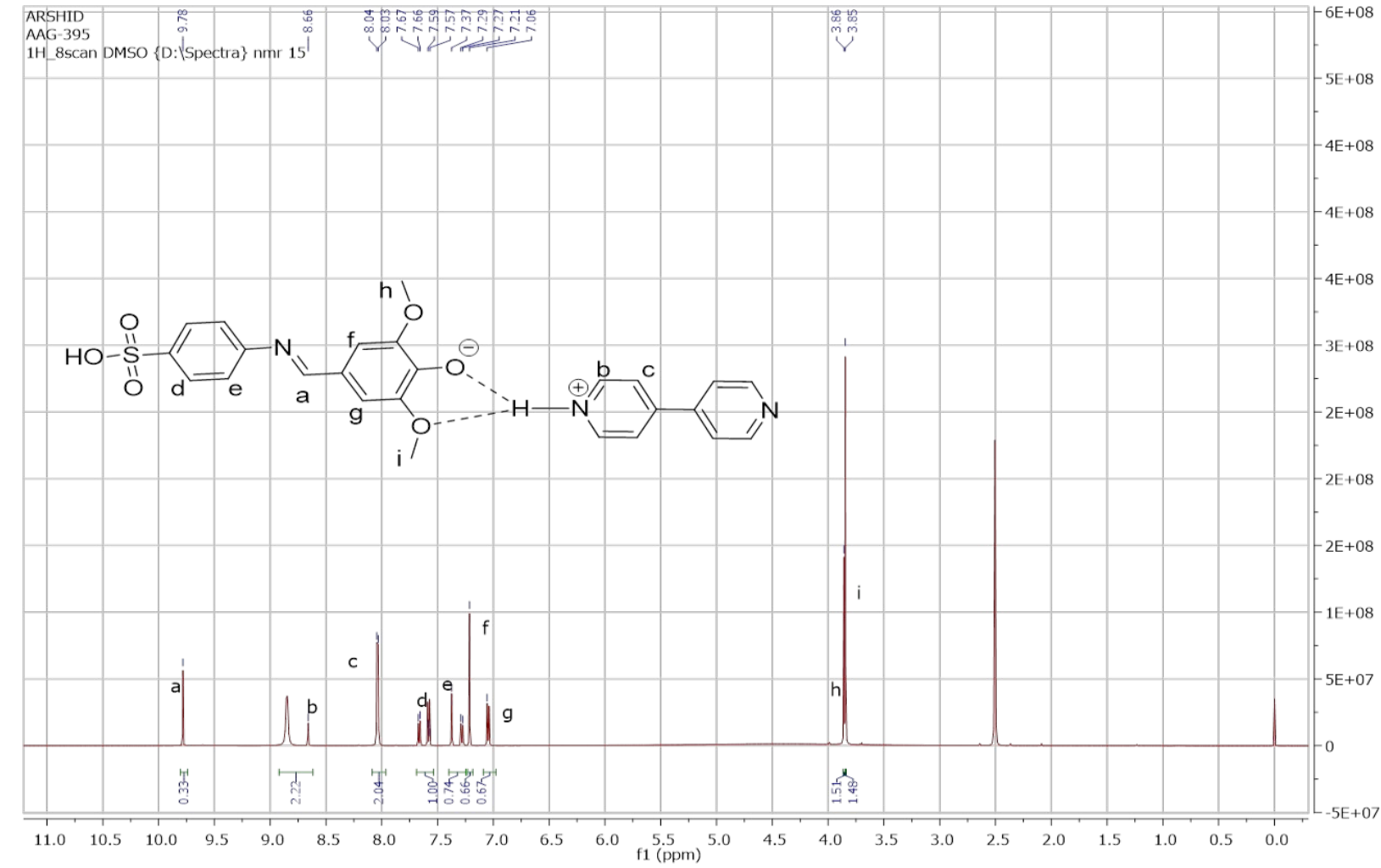

Figure ESI-10: ${ }^{1} \mathrm{H}-\mathrm{NMR}$ spectrum of 2 reported in $\mathrm{DMSO}-\mathrm{d}_{6}$ at $500 \mathrm{MHz}$.

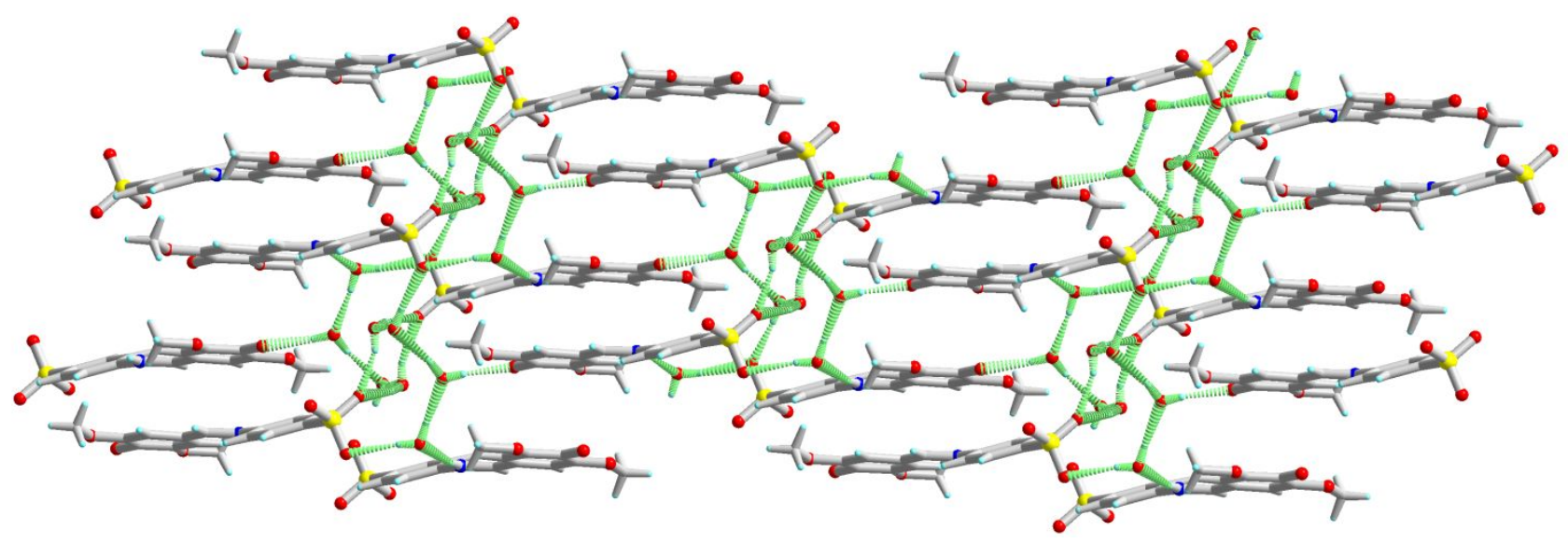

Figure ESI-11. 2D Network formed by sulfonate ions with aid of lattice water molecules in 1. 


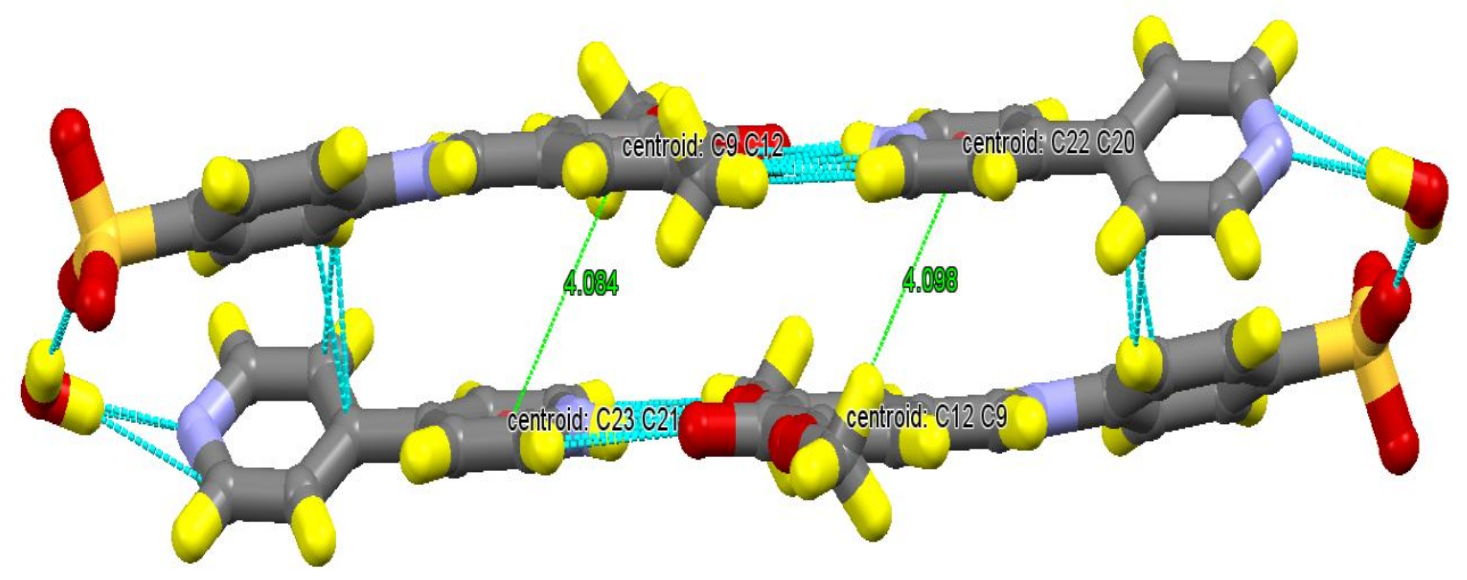

Figure ESI-12. Cyclic molecular cluster in 2.

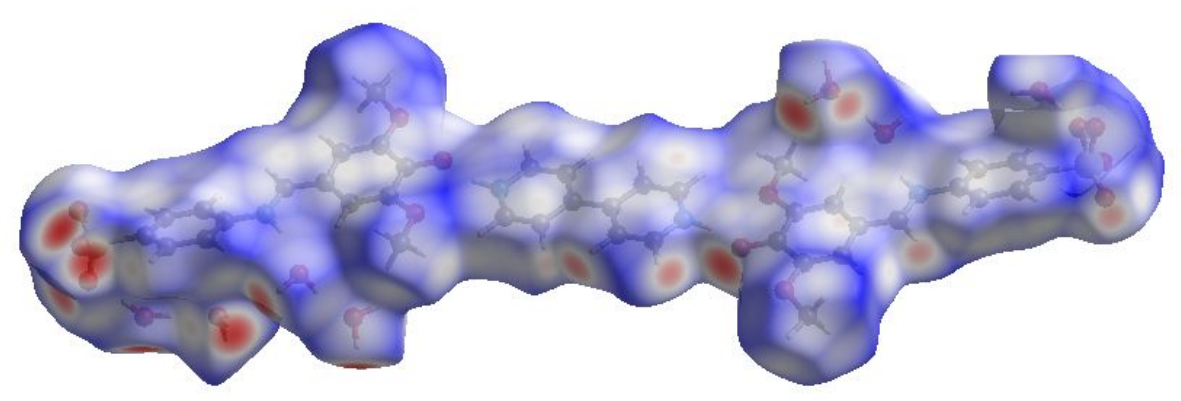

Figure ESI-13:Hirshfeld Surface of 1.

Table ESI-1:Hirshfeld surface property information of $\mathbf{1 .}$

\begin{tabular}{|c|c|c|c|c|}
\hline Name & Minimum & Mean & Maximum & Units \\
\hline $\mathrm{d}_{\mathrm{i}}$ & 0.717 & 1.625 & 2.433 & $\AA$ \\
\hline$d_{e}$ & 0.719 & 1.639 & 2.371 & $\AA$ \\
\hline $\mathrm{d}_{\text {norm }}$ & -0.635 & 0.394 & 1.230 & \\
\hline Shape index & -0.993 & 0.204 & 0.999 & \\
\hline Curvedness & -4.104 & -1.004 & 0.873 & \\
\hline
\end{tabular}



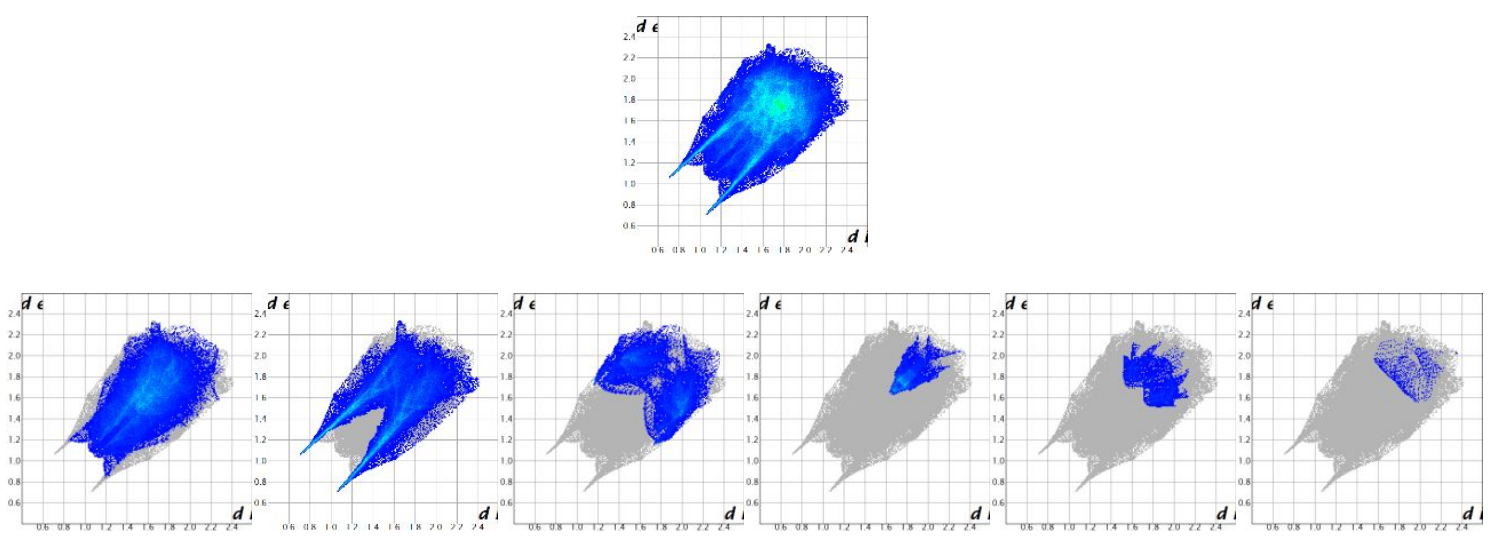

$\mathrm{H}-\mathrm{H} 38.5 \% \quad \mathrm{O}-\mathrm{H} / \mathrm{H}-\mathrm{O} 36.5 \% \quad \mathrm{C}-\mathrm{H} / \mathrm{H}-\mathrm{C}$ 13.8\% C-C 4.6\%C-O/O-H 3.2\% N-H/H-N 0.5\%

Figure ESI-14: Total and individual figerprint plots of 1 .

Table ESI-2: Percentage of total surface area for close contacts between atoms inside and outside in 1.

\begin{tabular}{lllllll} 
Inside & \multicolumn{2}{l}{ Outside atoms } & \multicolumn{2}{l}{} \\
atoms & $\mathrm{S}$ & $\mathrm{O}$ & $\mathrm{H}$ & $\mathrm{N}$ & $\mathrm{C}$ & Total \\
$\mathrm{C}$ & 0.0 & 1.7 & 7.4 & 1.1 & 4.6 & 14.9 \\
$\mathrm{H}$ & 0.0 & 16.9 & 38.5 & 0.2 & 6.4 & 62.0 \\
$\mathrm{~N}$ & $\cdot$ & 0.2 & 0.3 & $\cdot$ & 1.1 & 1.6 \\
$\mathrm{O}$ & $\cdot$ & 0.2 & 19.6 & 0.2 & 1.5 & 21.5 \\
$\mathrm{~S}$ & $\cdot$ & $\cdot$ & 0.0 & $\cdot$ & 0.0 & 0.0 \\
Total & 0.0 & 19.1 & 65.9 & 1.5 & 13.6 &
\end{tabular}

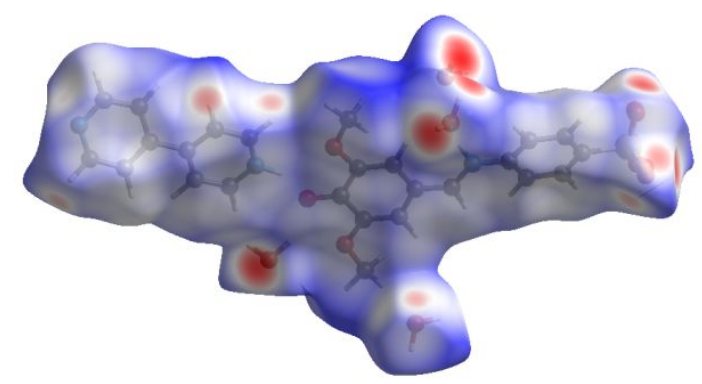

Figure ESI-15:Hirshfeld Surface of 2. 
Table ESI-3:Hirshfeld surface property information of $\mathbf{2}$.

\begin{tabular}{lllll} 
Name & Minimum & Mean & Maximum & Units \\
\hline $\mathrm{d}_{\mathrm{i}}$ & 0.723 & 1.632 & 2.433 & $\AA$ \\
\hline $\mathrm{d}_{\mathrm{e}}$ & 0.725 & 1.647 & 2.498 & $\AA$ \\
\hline $\mathrm{d}_{\text {norm }}$ & -0.628 & 0.386 & 1.338 & \\
\hline Shape index & -0.997 & 0.214 & 0.999 & \\
\hline Curvedness & -4.028 & -0.990 & 0.550 &
\end{tabular}
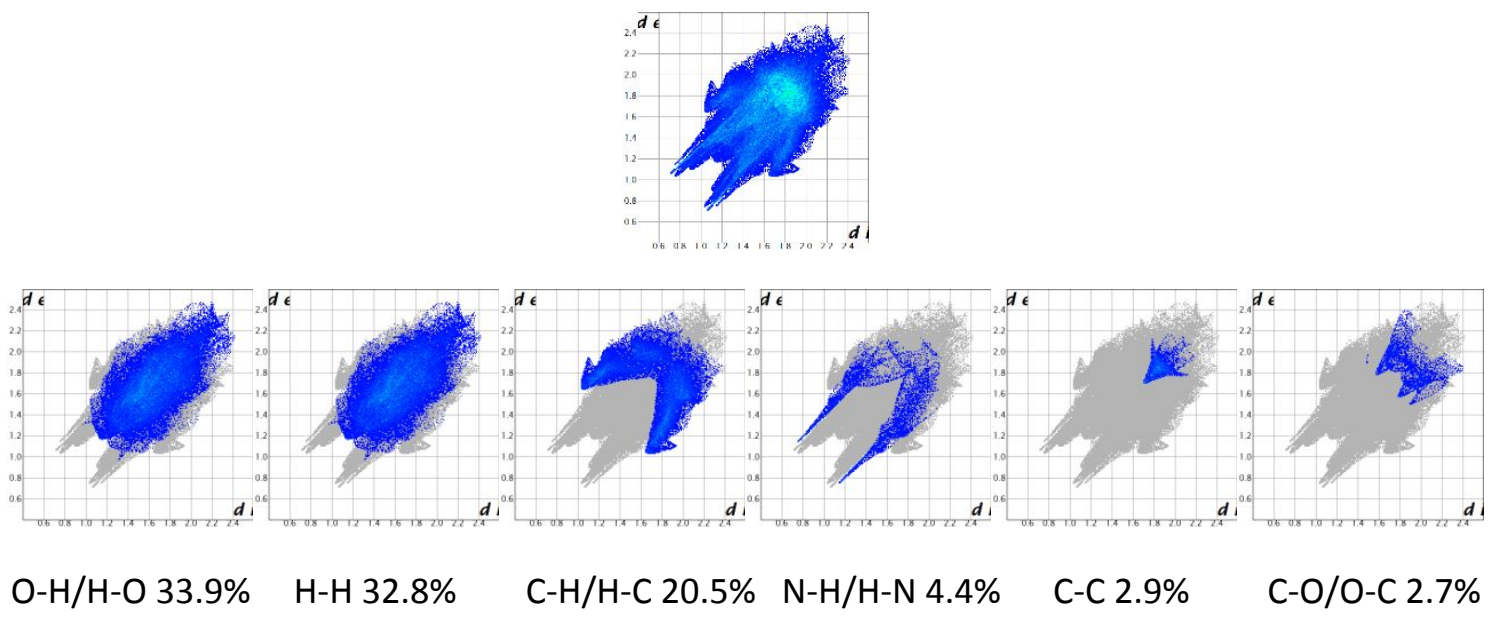

Figure ESI-16: Total and individual figerprint plots of 2. 
Table ESI-4:Percentage of total surface area for close contacts between atoms inside and outside in 2.

\begin{tabular}{lllllll} 
Inside & \multicolumn{2}{l}{ Outside atoms } & \multicolumn{2}{l}{} \\
atoms & $\mathrm{S}$ & $\mathrm{O}$ & $\mathrm{H}$ & $\mathrm{N}$ & $\mathrm{C}$ & Total \\
\hline $\mathrm{C}$ & $\cdot$ & 1.4 & 11.4 & 1.0 & 2.9 & 16.8 \\
$\mathrm{H}$ & $\cdot$ & 16.6 & 32.8 & 2.0 & 9.5 & 60.8 \\
$\mathrm{~N}$ & $\cdot$ & 0.0 & 2.4 &. & 1.0 & 3.5 \\
\hline $\mathrm{O}$ & $\cdot$ & 0.4 & 17.3 &. & 1.3 & 18.9 \\
$\mathrm{~S}$ & $\cdot$ &. &. &. &. & 0.0 \\
Total & 0.0 & 18.4 & 63.9 & 3.0 & 14.7 &
\end{tabular}

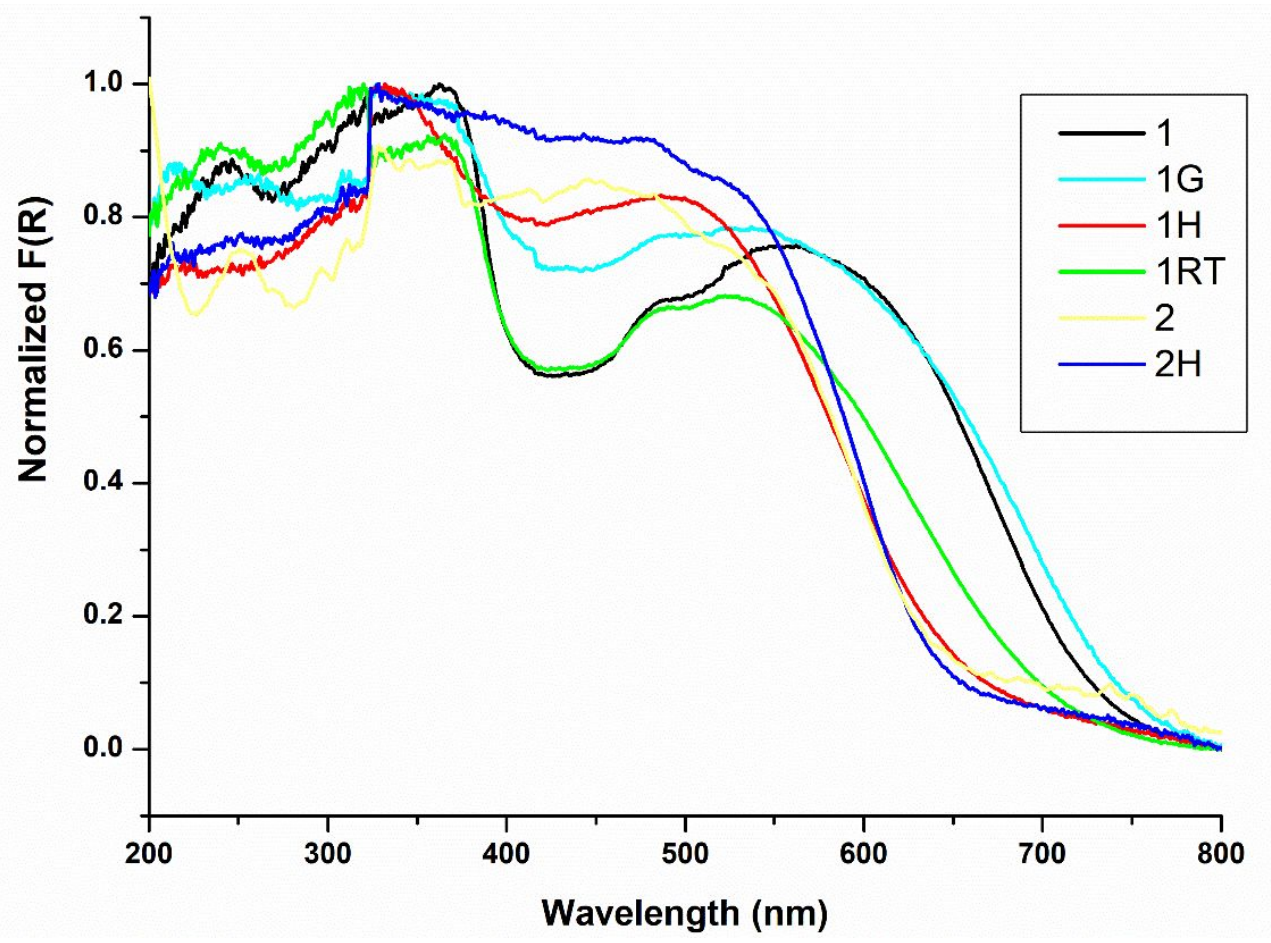

Figure ESI-17: MergedK-M plots of 1, 2 and their different forms. 


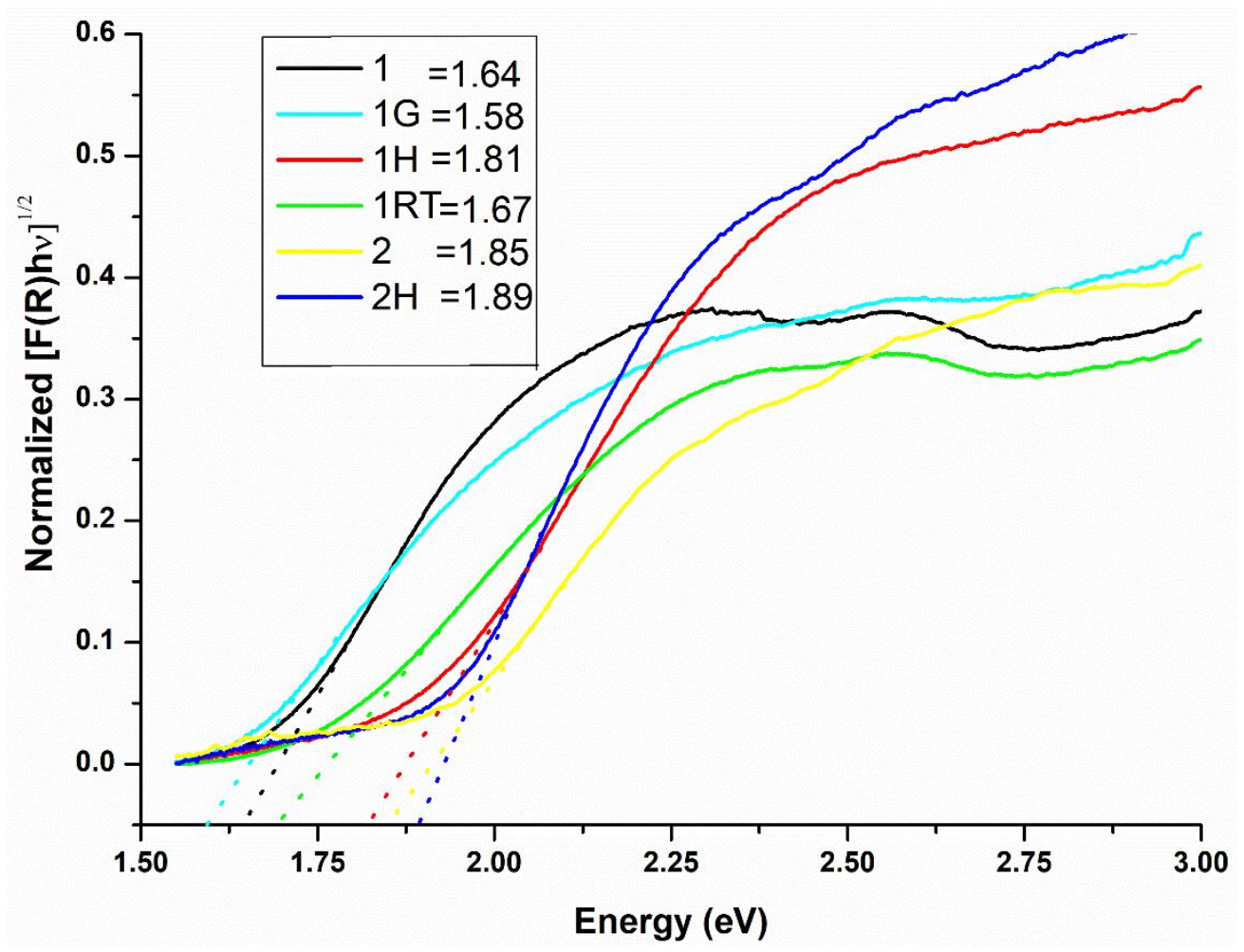

Figure ESI-18: MergedTauc of 1, 2 and their different forms.

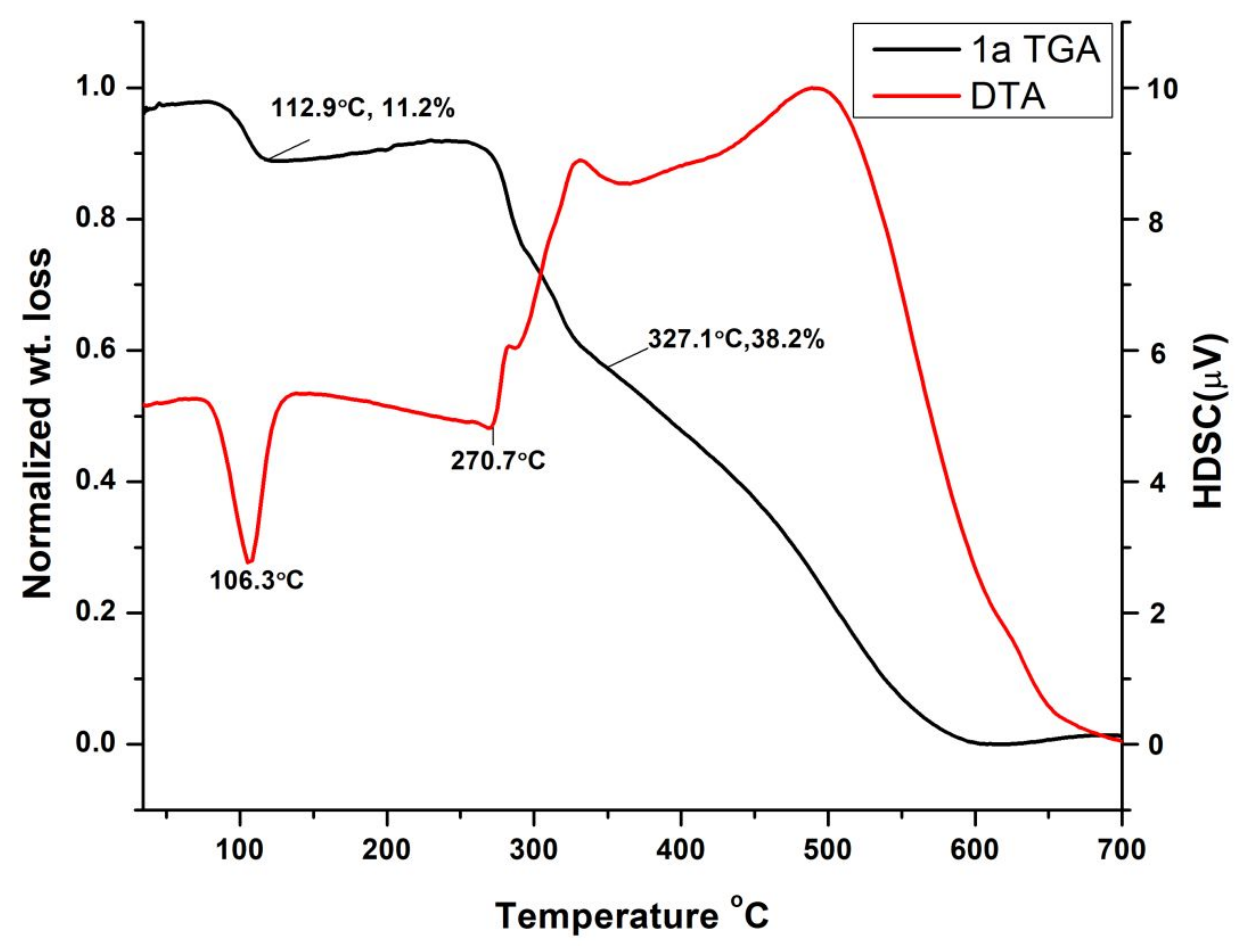

Figure ESI-19:TGA-DTA Thermograms of 1a. 


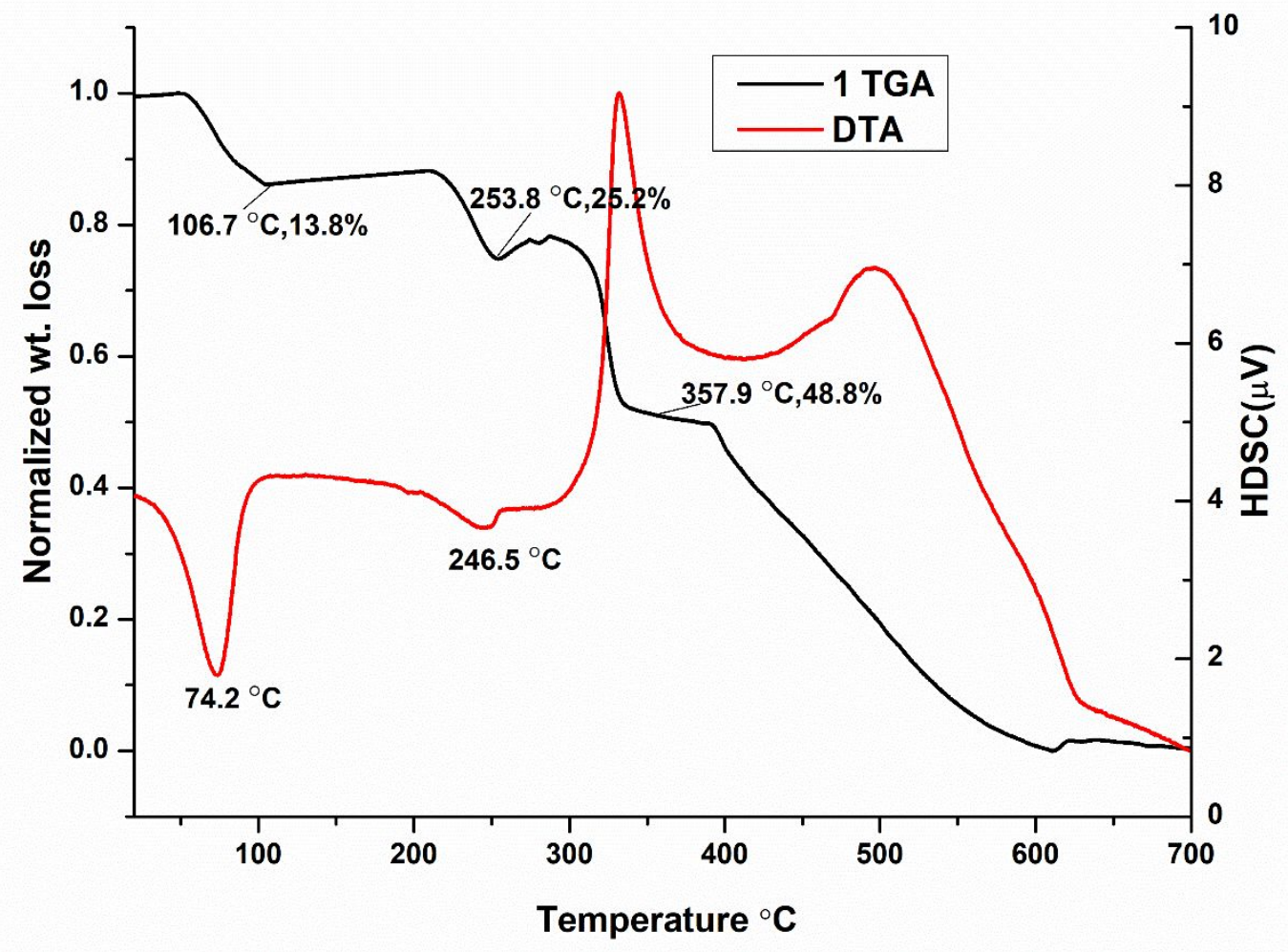

Figure ESI-20:TGA-DTA Thermograms of $\mathbf{1}$.

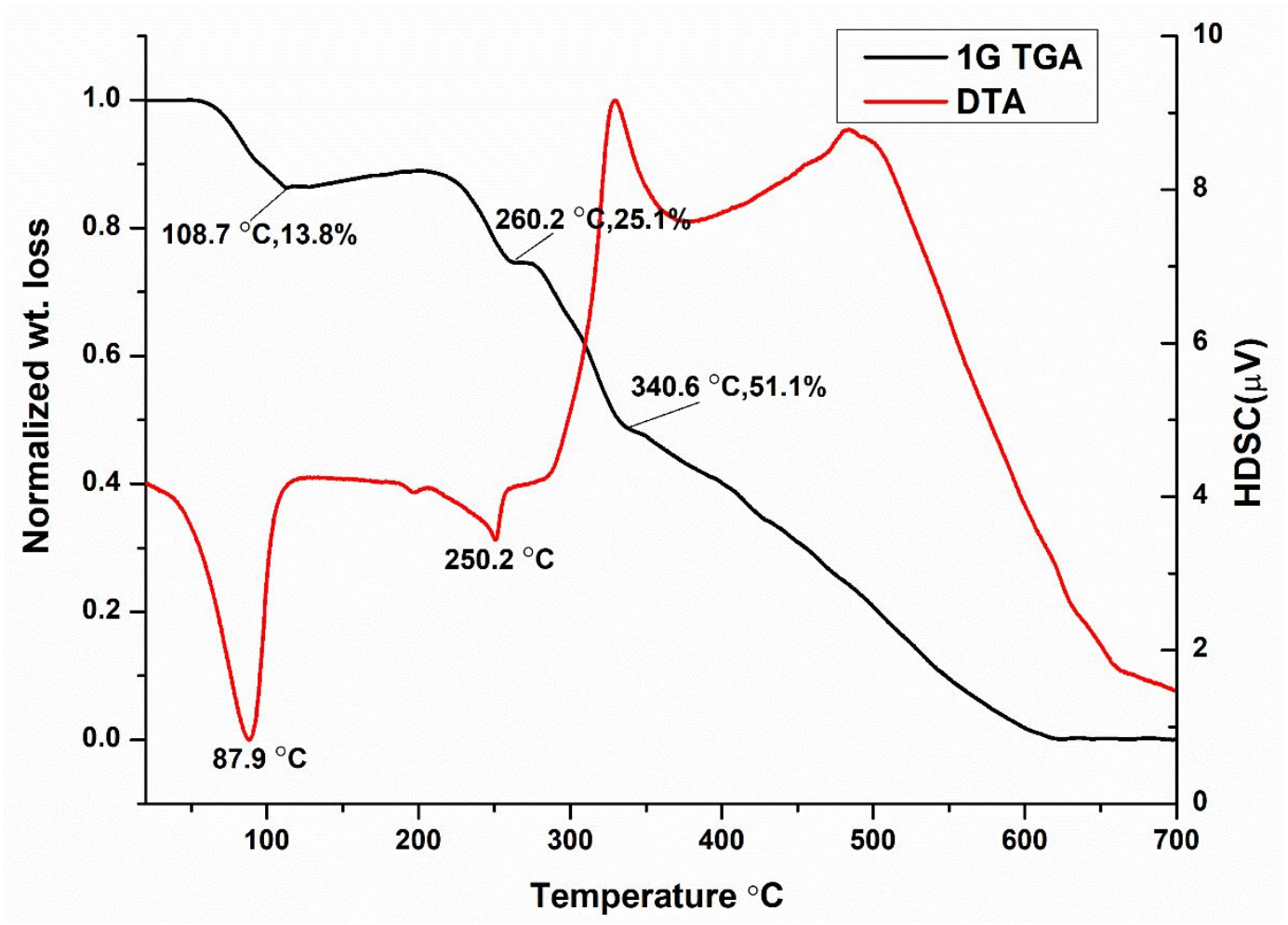

Figure ESI-21:TGA-DTA Thermograms of 1G. 


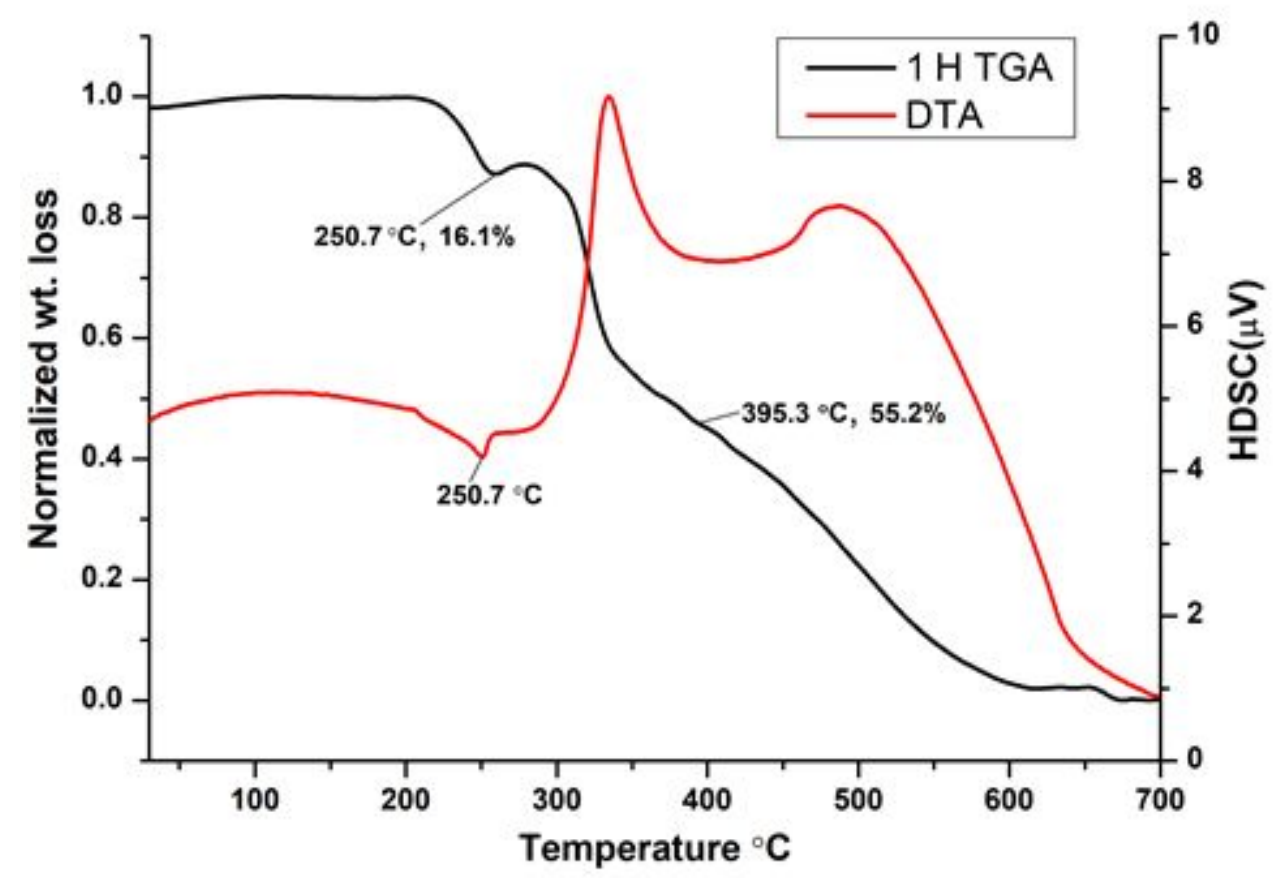

Figure ESI-22:TGA-DTA Thermograms of $\mathbf{1 H}$.

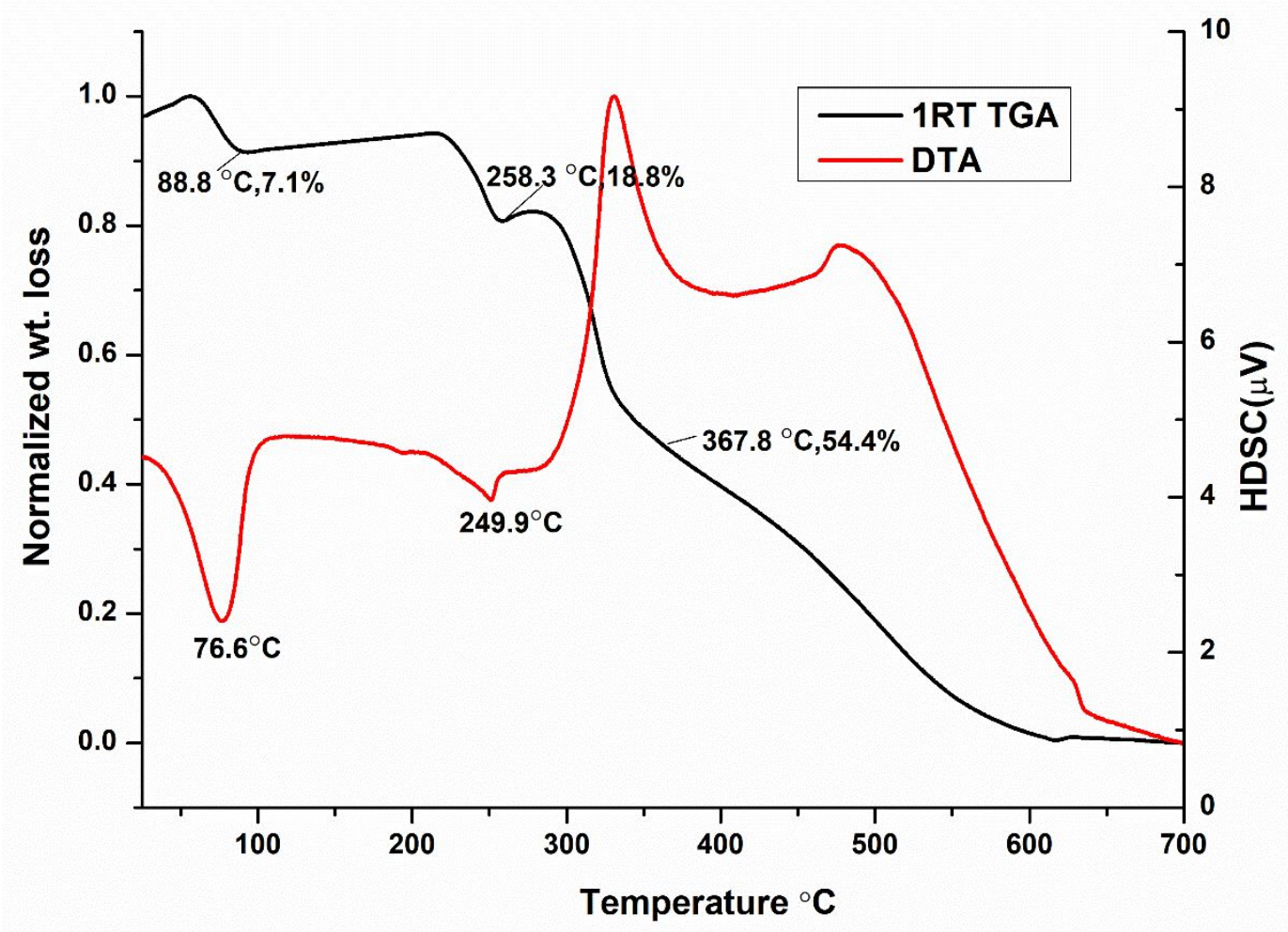

Figure ESI-23: TGA-DTA Thermograms of 1RT. 


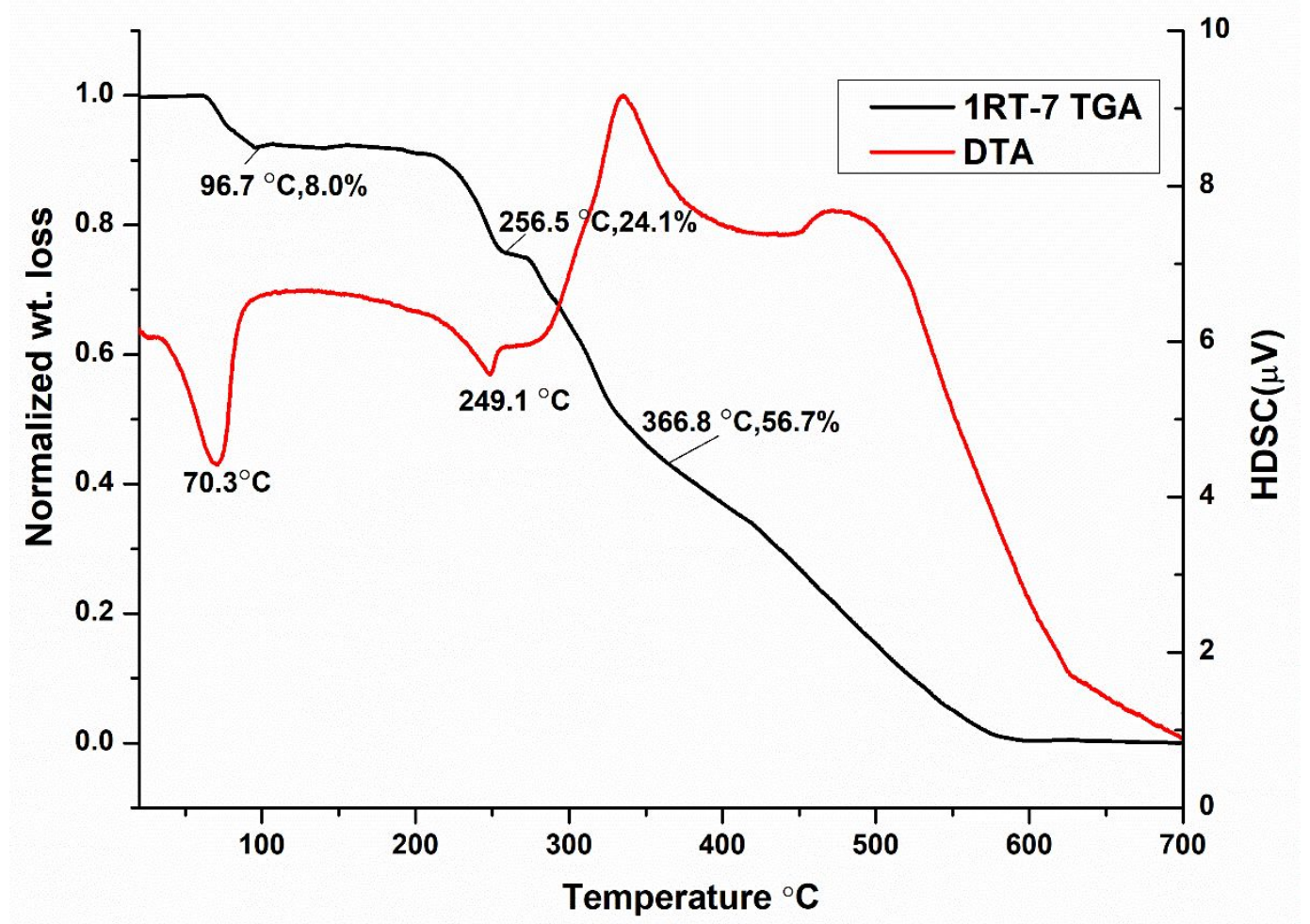

Figure ESI-24:TGA-DTA Thermograms of 1RT-7.

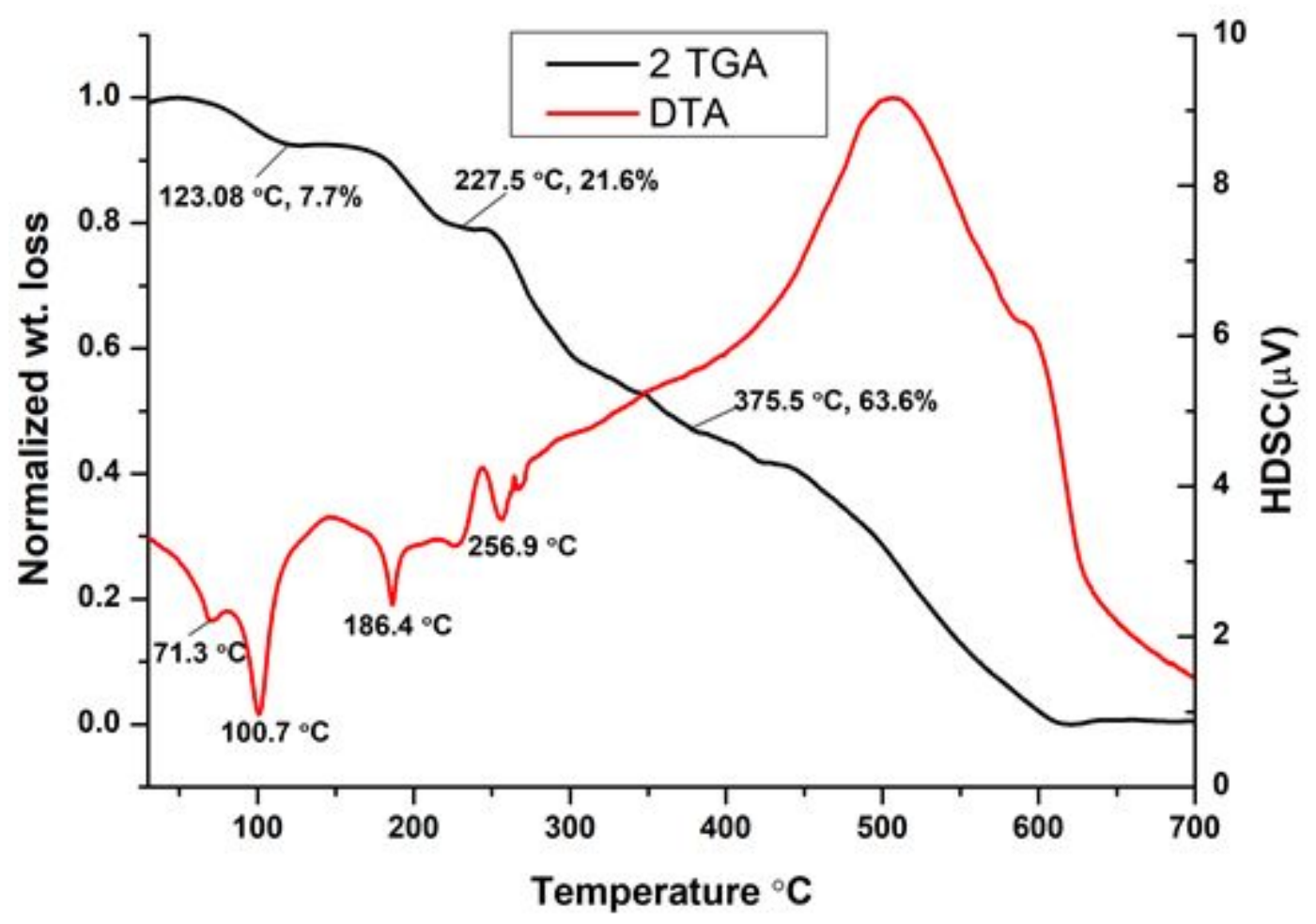

Figure ESI-25:TGA-DTA Thermograms of 2. 


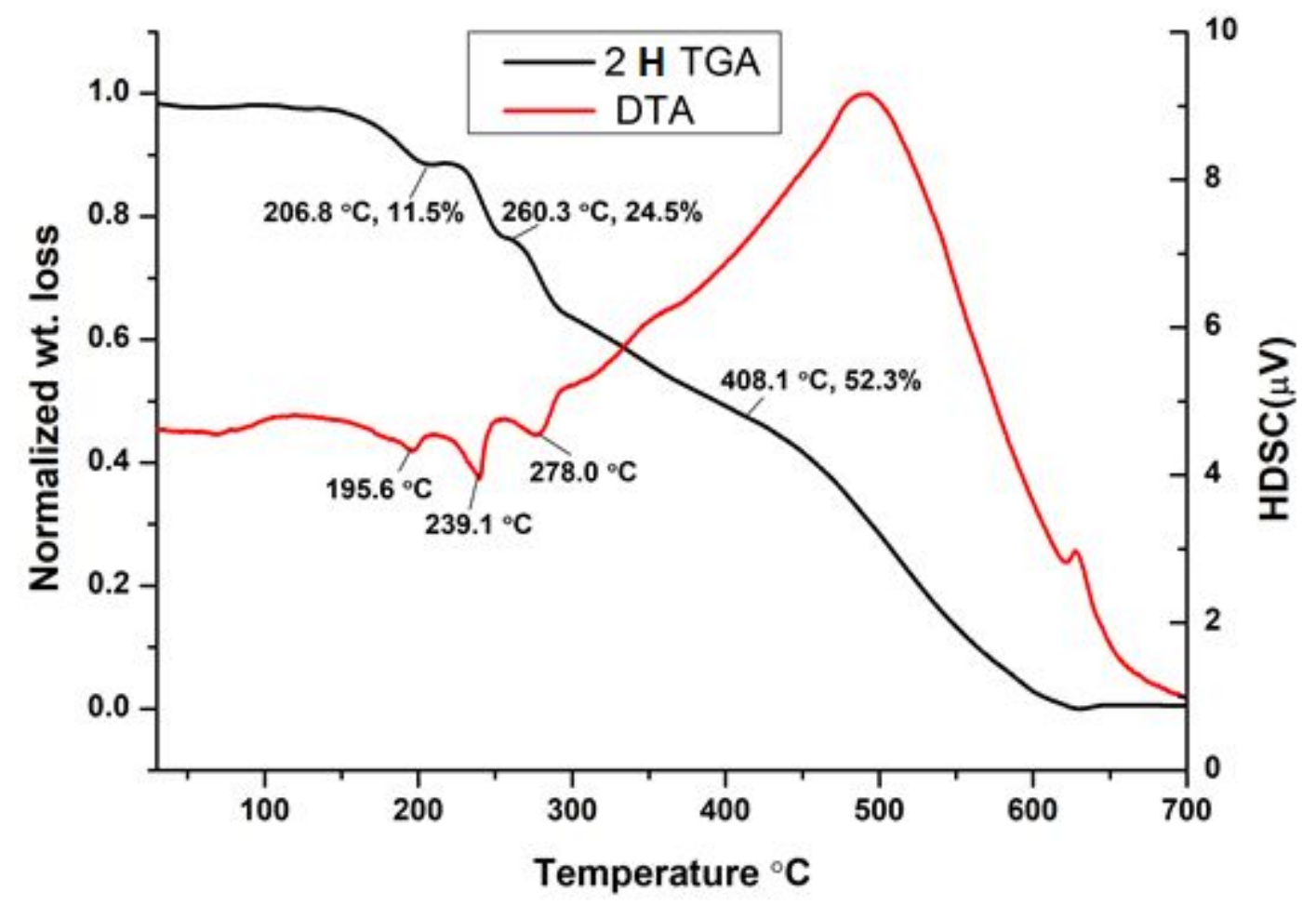

Figure ESI-26:TGA-DTA Thermograms of $\mathbf{2 H}$.

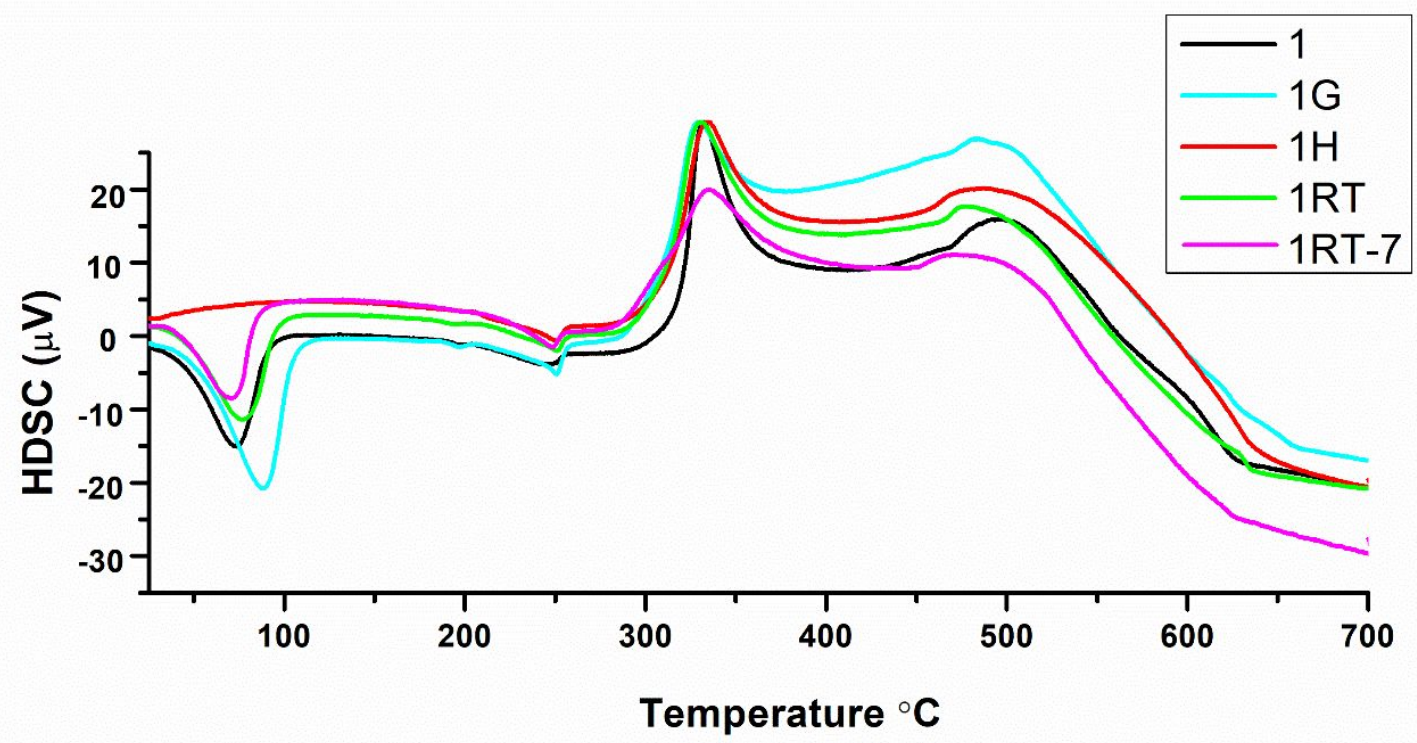

Figure ESI-27: Merged DTA curves of 1 and its different forms. 


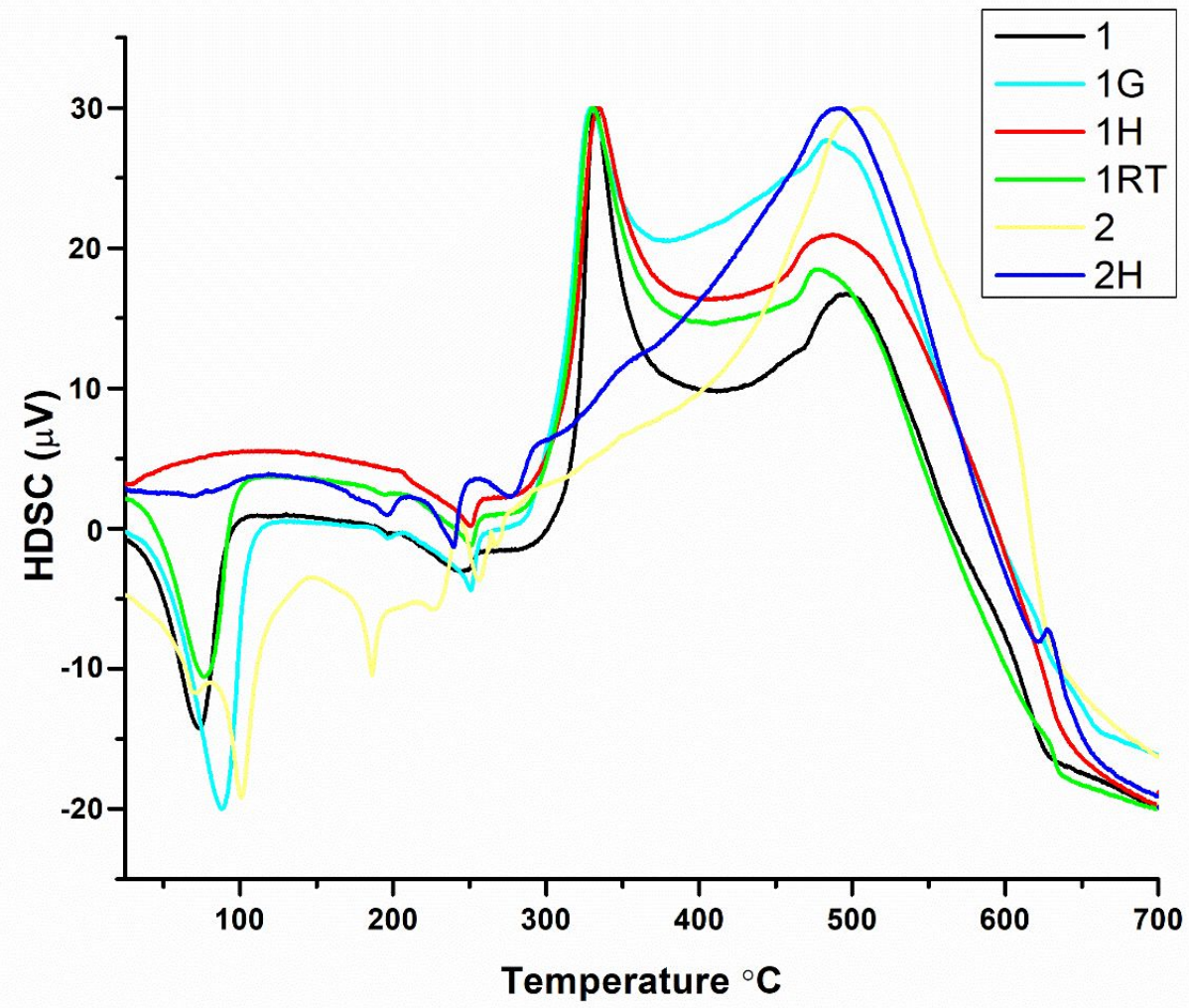

Figure ESI-28: Merged DTA curves of 1, 2 and their different forms.

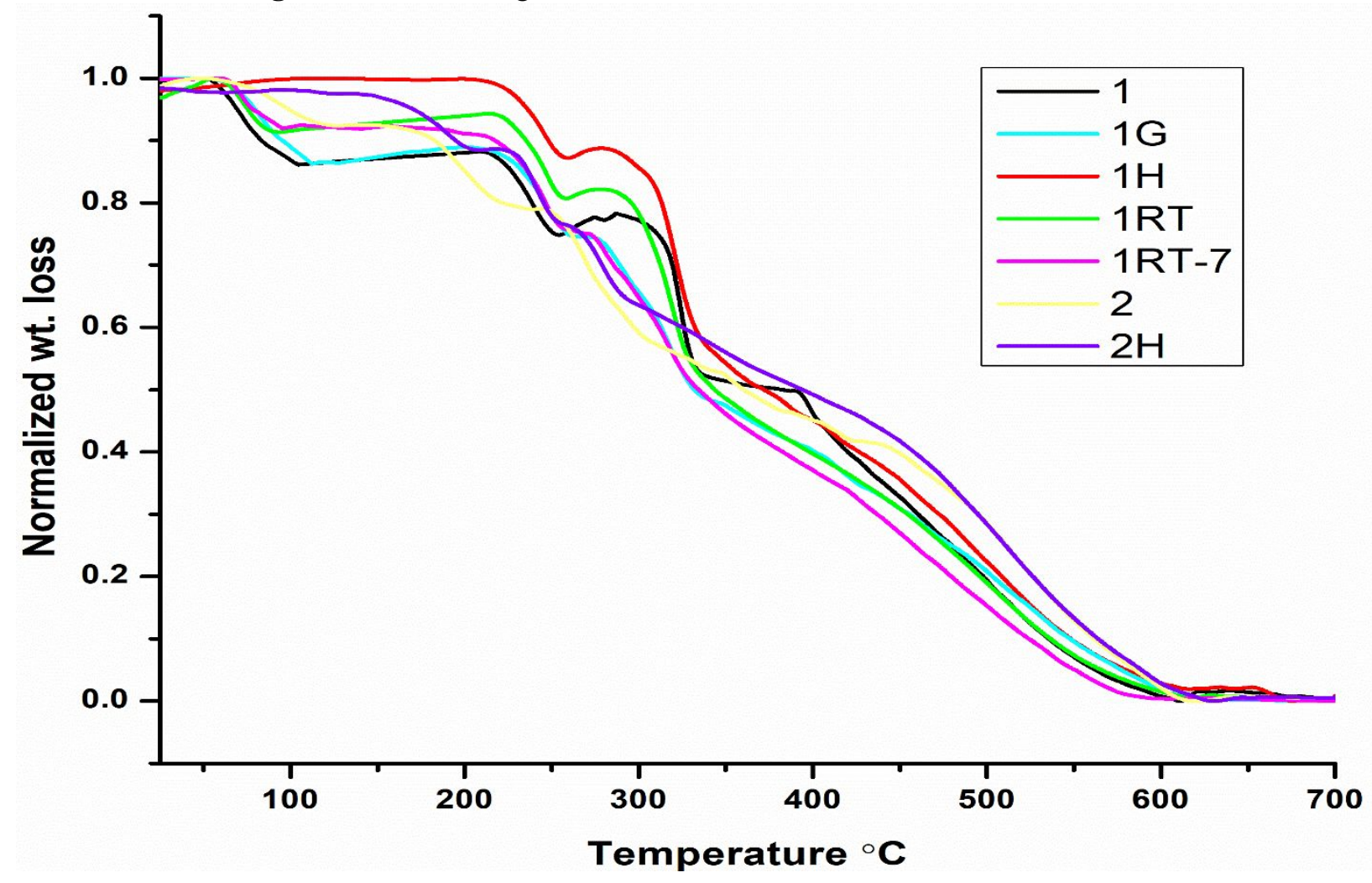

Figure ESI-29: Merged TGA Thermograms of 1, 2 and their different forms. 


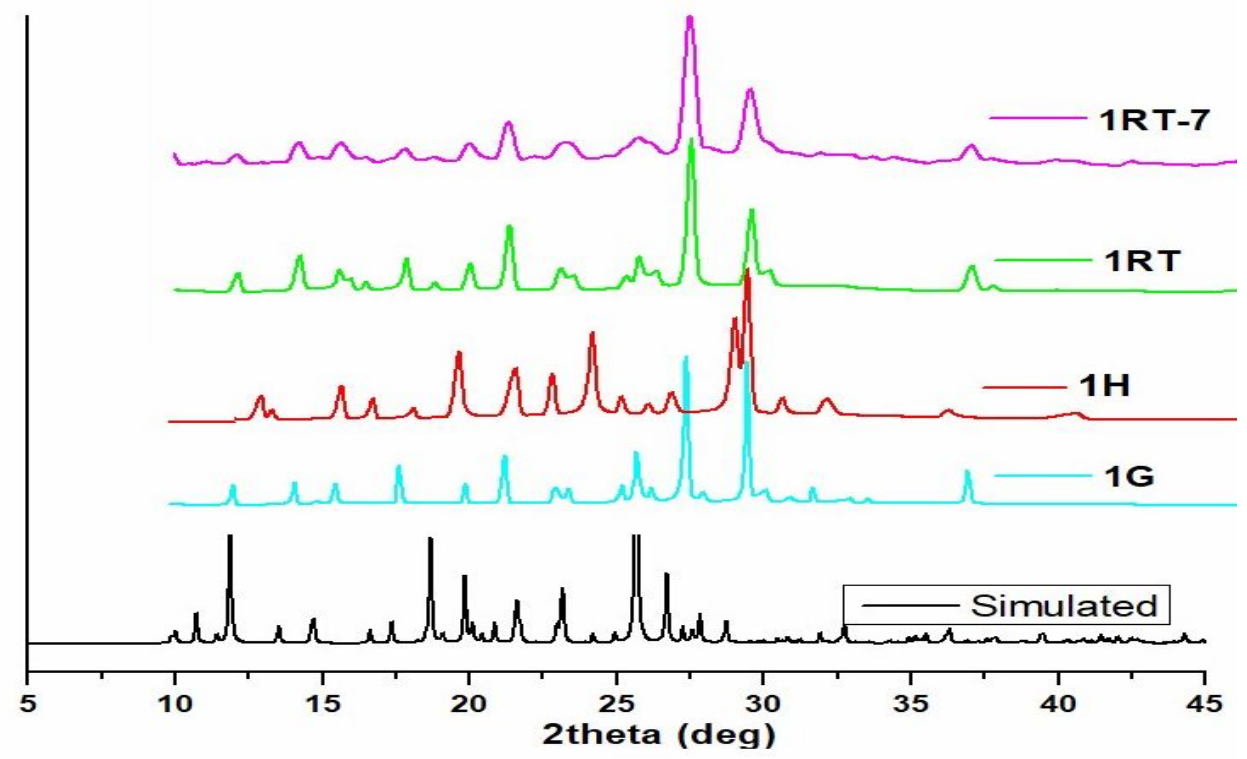

Figure ESI-30: Comparative P-xrd plots 1 and its different forms. 